University of Tennessee Health Science Center

UTHSC Digital Commons

\title{
The mGluR2/3 Agonist LY397268 Improves Morphometric and Behavioral Outcomes in R6/2 Huntington's Disease Mice
}

Dennis Craig Lafferty

University of Tennessee Health Science Center

Follow this and additional works at: https://dc.uthsc.edu/dissertations

Part of the Medical Anatomy Commons, Nervous System Diseases Commons, and the Neurosciences Commons

\section{Recommended Citation}

Lafferty, Dennis Craig, "The mGluR2/3 Agonist LY397268 Improves Morphometric and Behavioral Outcomes in R6/2 Huntington's Disease Mice" (2010). Theses and Dissertations (ETD). Paper 152. http://dx.doi.org/10.21007/etd.cghs.2010.0170.

This Thesis is brought to you for free and open access by the College of Graduate Health Sciences at UTHSC Digital Commons. It has been accepted for inclusion in Theses and Dissertations (ETD) by an authorized administrator of UTHSC Digital Commons. For more information, please contact jwelch30@uthsc.edu. 


\title{
The mGluR2/3 Agonist LY397268 Improves Morphometric and Behavioral Outcomes in R6/2 Huntington's Disease Mice
}

\author{
Abstract \\ A prominent theory for the pathology of Huntington's Disease (HD) is the excitotoxic injury to the striatum. \\ Continual exposure of ionotropic NMDA receptors to glutamate from the cortex can be excitotoxic in HD \\ and leave striatal neurons vulnerable to damage. Activation of presynaptic mGluR2/3 by an agonist \\ dampens glutamate release from corticostriatal terminals. Treatments that target excitoxicity and \\ oxidative stress thus may improve some of the symptoms in HD patients and it is therefore logical to \\ pursue therapies aimed in this direction. LY379268 is an inviting mGluR2/3 agonist that has been shown \\ to be neuroprotective in hypoxic and ischemic injuries to cultured neurons. Daily subcutaneous injection \\ of $20 \mathrm{mg} / \mathrm{kg} \mathrm{LY} 379268$ had a number of beneficial effects in R6/2 mice, including an $11 \%$ improvement in \\ lifespan and various locomotor parameters. The drug showed improvement in open field measurements \\ of overall activity, speed, acceleration, and endurance. Histological and tissue analysis revealed a reduced \\ lateral ventricle enlargement when compared to vehicle-treated R6/2 mice. There was a $20 \%$ loss of \\ cortical and striatal neurons in R6/2 mice, which was rescued with the administration of LY379268. There \\ was no effect of the drug on neuronal intranuclear inclusions (NIIs) or ENK+ striatal neurons, but SP+ \\ striatal projection neurons were normalized in their neurochemistry. The R6/2 data indicate that \\ LY379268 is particularly useful in improving the health and functioning of the direct striatal pathway (i.e. \\ $\mathrm{SP}+$ neurons), which demonstrably improved the voluntary motor behavior in the R6/2 mice.

\section{Document Type} \\ Thesis

\section{Degree Name} \\ Master of Science (MS)

\section{Program} \\ Biomedical Sciences \\ Research Advisor \\ Anton Reiner, Ph.D. \\ Keywords \\ Basal Ganglia, Huntington's Disease

\section{Subject Categories} \\ Diseases | Medical Anatomy | Medical Sciences | Medicine and Health Sciences | Nervous System \\ Diseases | Neurosciences
}


The mGluR2/3 Agonist LY397268 Improves Morphometric and Behavioral Outcomes in R6/2 Huntington's Disease Mice

\author{
A Thesis \\ Presented for \\ The Graduate Studies Council \\ The University of Tennessee \\ Health Science Center \\ In Partial Fulfillment \\ Of the Requirements for the Degree \\ Master of Science \\ From The University of Tennessee
}

By

Dennis Craig Lafferty

December 2010 
Copyright (C) 2010 by Dennis Craig Lafferty. All rights reserved. 


\section{ACKNOWLEDGMENTS}

I would like to express my gratitude to everyone who has helped me in my endeavor of pursuing a Master of Science degree. To Dr. Anton Reiner, without his immense knowledge and hard work, this research project would not have been possible. To my committee members, Dr. Angela Cantrell and Dr. Ioannis Dragatsis for their advice and experience. To the other members of the Reiner lab, for their constant care and mentorship. Lastly, I must thank my family for their love and support. 


\begin{abstract}
A prominent theory for the pathology of Huntington's Disease (HD) involves excitotoxic injury to the striatum. Continuous exposure of ionotropic NMDA receptors to glutamate from the cortex may occur and be excitotoxic in HD and leave striatal neurons vulnerable to damage. Activation of presynaptic mGluR2/3 receptors by an agonist dampens glutamate release from corticostriatal terminals. Treatments that target excitoxicity thus may improve symptoms in HD patients, and it is therefore logical to pursue therapies aimed in this direction. LY379268 is an inviting mGluR2/3 receptor agonist that has been shown to be neuroprotective in hypoxic and ischemic injuries to cultured neurons. Daily subcutaneous injection of 20mg/kg LY379268 had a number of beneficial effects in R6/2 mice, including an 11\% improvement in lifespan and numerous locomotor parameters in open field. The motor parameters improved included overall activity, speed, acceleration, and endurance, all of which were normalized until 12 weeks of age, and improved over vehicle-treated R6/2 mice at all ages. Histological analysis revealed a $20 \%$ loss of cortical and striatal neurons in R6/2 mice, which was rescued with the administration of LY379268. There was no effect of the drug on neuronal intranuclear inclusions (NIIs) or benefit for ENK+ striatal neuron neurochemistry, but SP+ striatal projection neurons were normalized in their neurochemistry. The data indicate that LY379268 is particularly useful in improving the health and functioning of the direct striatal pathway (i.e. SP+ neurons), which demonstrably improved the voluntary motor behavior in the R6/2 mice.
\end{abstract}




\section{TABLE OF CONTENTS}

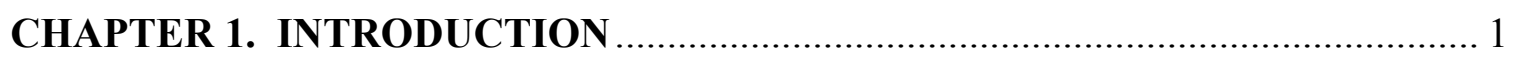

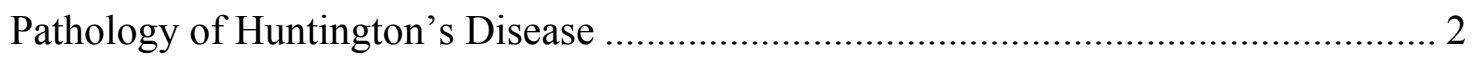

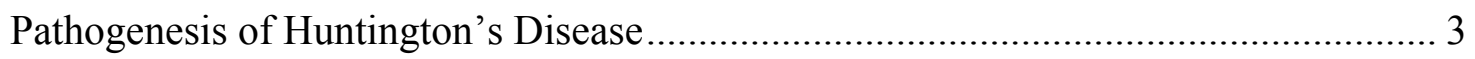

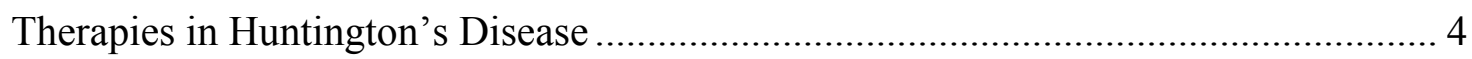

CHAPTER 2. RESEARCH OBJECTIVES AND SPECIFIC AIMS …………......... 7

CHAPTER 3. EXPERIMENTAL PROCEDURES …………………………......... 9

Subjects

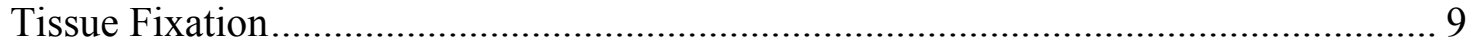

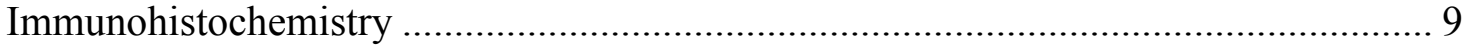

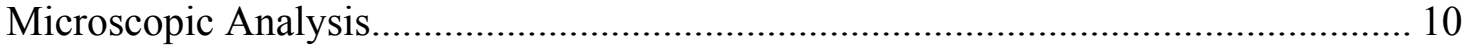

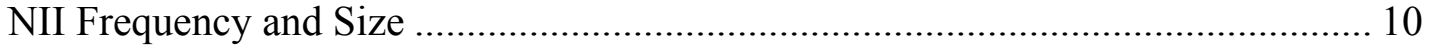

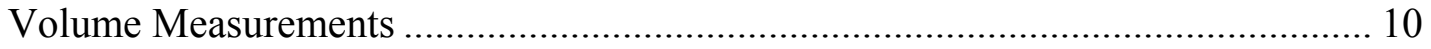

Image Analysis of Immunolabeling in Striatal Target Areas .................................... 11

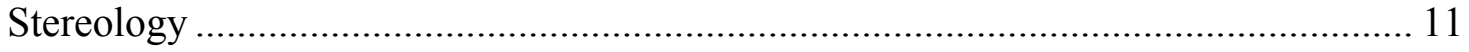

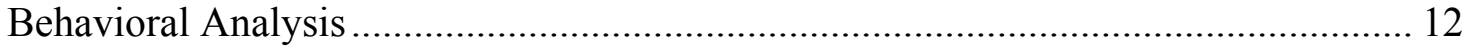

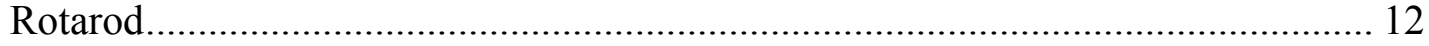

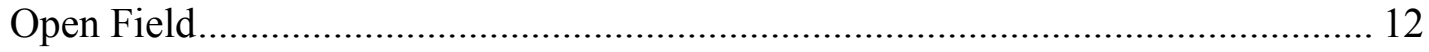

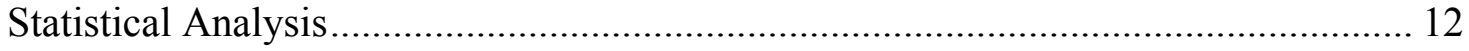

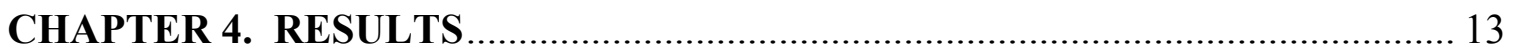

Histological Studies of Fixed Tissue ................................................................. 13

Volumetric Analysis ................................................................................. 13

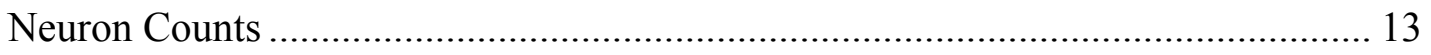

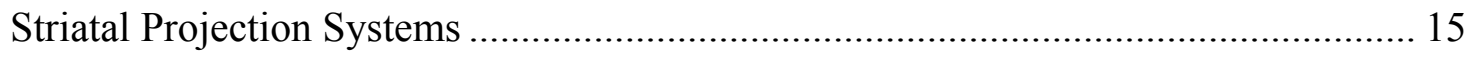

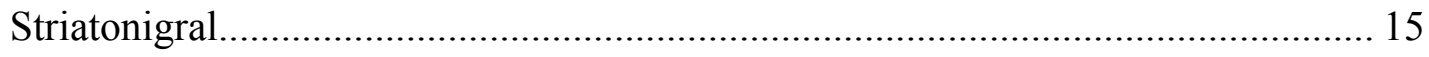

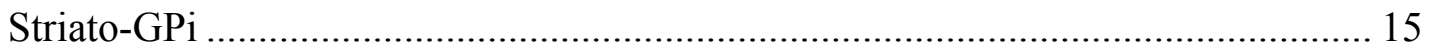

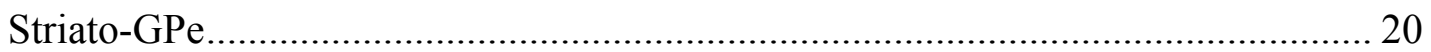

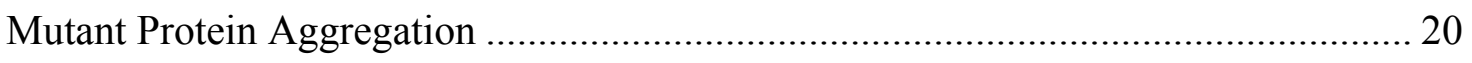

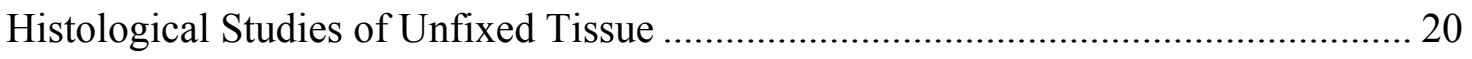

ENK In Situ Hybridization Analysis................................................................. 22

SP In Situ Hybridization Analysis ................................................................... 22 


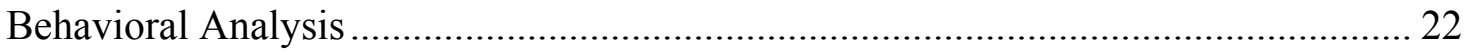

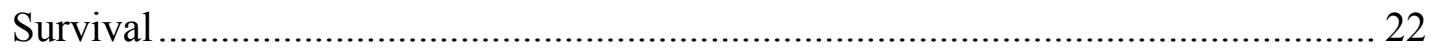

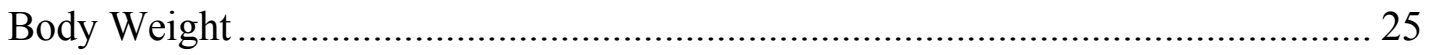

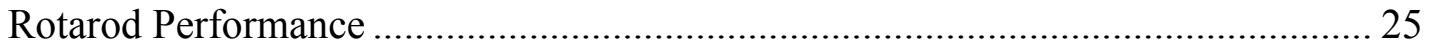

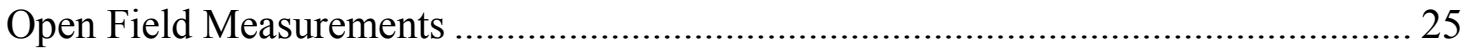

Total Distance Traveled in Centimeters during 30 Minutes .................................. 25

Median Progression Segment Length ............................................................. 29

Time Proportion Spent Lingering ....................................................................... 29

Progression Segment Maximum Speed ............................................................. 29

Median Curvature of Progression Segments......................................................... 29

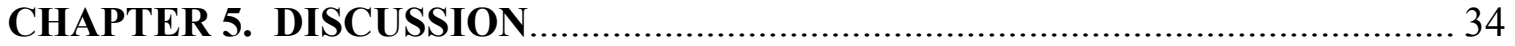

Neuropathology and Behavior Correlations .......................................................... 34

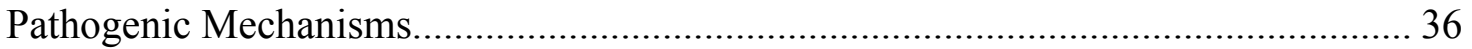

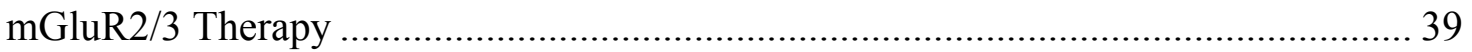

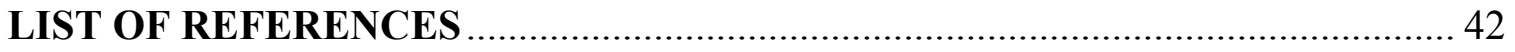

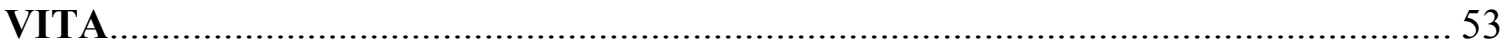




\section{LIST OF TABLES}

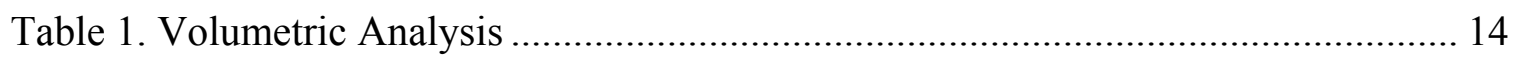

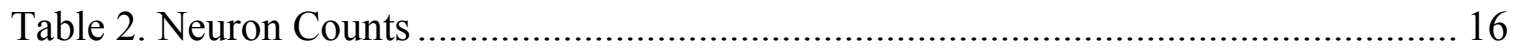

Table 3. Effect of LY379268 on Striatal Projection Neurons in Nigra of R6/2 Mice...... 17

Table 4. Effect of LY379268 on Striatal Projection Neurons in GPi of R6/2 Mice......... 19

Table 5. Effect of LY379268 on Strial Projection Neurons in GPe of R6/2 Mice.......... 21

Table 6. LY379268 on ENK in Striatal Projection Neurons as a \% of WT-Vehicle ....... 23

Table 7. LY379268 on SP in Striatal Projection Neurons as a \% of WT-Vehicle ........... 23 


\section{LIST OF FIGURES}

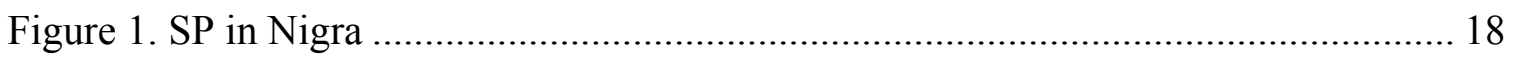

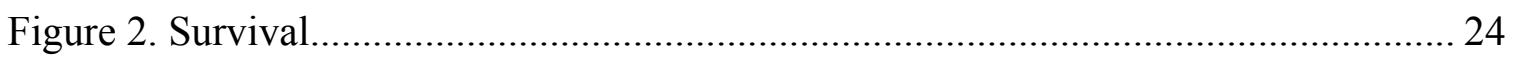

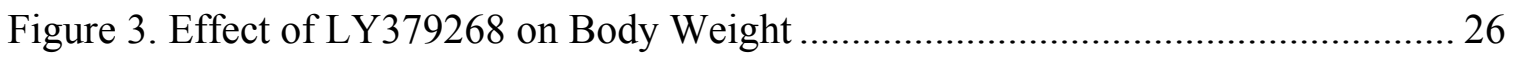

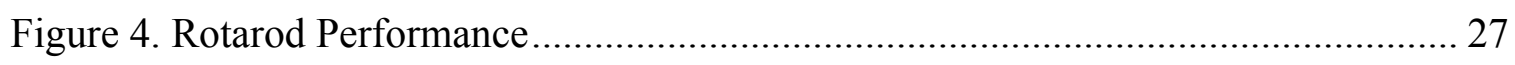

Figure 5. Total Distance Traveled in Centimeters during 30 Minute Session.................. 28

Figure 6. Median Progression Length............................................................... 30

Figure 7. Time Proportion Spent Lingering............................................................ 31

Figure 8. Maximum Progression Speed ............................................................. 32

Figure 9. Median Curvature of Progression................................................................ 33 


\section{LIST OF ABBREVIATIONS}

AMPA

BDNF

ENK

GABA

GPe

HD

$\mathrm{Htt}$

Mhtt

MSN

NIIs

NMDA

$\mathrm{SN}$

SP

WT

3-NP $\alpha$-amino-3-hydroxy-5-methyl-4-isoxazolepropionate Briain Derived Neurotropic Factor Enkephalin Gamma-Aminobutyric Acid Globus Pallidus Externus Huntington's Disease Huntingtin Mutant Huntingtin Medium Spiny Neurons Neuronal Intranuclear Inclusions N-methyl-D-asparate Substantia Nigra Substance P Wild Type 3-Nitroproprionic Acid 


\section{CHAPTER 1. INTRODUCTION}

Huntington's disease (HD) is an inherited neurodegenerative disorder resulting in motor, cognitive and psychiatric abnormalities. The progressive nature of the disease eventually leads to a disorder of extrapyramidal movement that includes the uncontrolled dance like motion of chorea, and later rigidity and dystonia (Cepeda et al 2007; Vonsattel \& DiFiglia 1998). Chorea is an early characteristic symptom which can be defined as excessive spontaneous movement with abrupt irregular timing. It is repetitive in nature and all parts of the body can be affected by this symptom. Dystonia is another motor abnormality seen later in HD with sustained muscular contraction. Depression is a frequent psychiatric symptom and often precedes the appearance of motor abnormalities. Over years, the motor symptoms predominantly worsen, such that walking, speaking and eating become more difficult. Average age of onset is usually mid-thirties to mid-forties and the disease lasts 15-20 years. This autosomal dominant disease stems from expanded polyglutamine (CAG) repeats in exon 1of the human HD gene (MacDonald 1993). CAG is the codon for glutamine, and this trinucleotide repeat is responsible for the polyglutamine moiety within the huntingtin protein. Normal range of the expanded glutamine (polyQ) tract is between 25-35 repeats, with HD symptoms appearing with polyQ tracts greater than 35 repeats (Group 1993). There is an inverse correlation between the length of the CAG repeats and the age of onset of HD (Group 1993; Telenius et al 1993), and repeat lengths greater than 70 produce an HD phenotype characterized by juvenile onset, and rigidity, dystonia and tremor as presenting symptoms.

Although the HD protein huntingtin (htt) was discovered over a decade ago, its function is still not fully understood. The protein coded by the HD gene is ubiquitously expressed throughout the body and has widespread subcellular localization, thus contributing to the difficulty in determining its function. However, many proteins interact with htt, which can offer clues to elucidate the function of htt and the pathogenesis of HD. These protein-protein interactions are based on the shape of the three-dimensional structure of huntingtin and the poly-Q expansion in the N-terminal region (Poirier et al 2005). Based on their known functions, htt-associated proteins can be grouped as proteins that are involved in gene transcription and proteins that are involved with intracellular signaling, trafficking, endocytosis or metabolism (Li \& Li 2004a). This involvement means that htt is associated with a variety of cellular structures including the nucleus, endoplasmic reticulum, Golgi complex, synaptic vesicles and mitochondria (DiFiglia et al 1995; Gutekunst et al 1998; Velier et al 1998). Wild type htt undergoes four types of post-translational modifications: sumoylation and ubiquination of lysines at the N-terminal, phosphorylation of serines; and palmitoylation at an unknown amino acid (Huang et al 2004; Humbert et al 2002; Kalchman et al 1996; Steffan et al 2004). Huntingtin also contains three protease cleavage sites leading to fragments of both normal and mutant huntingtin (mhtt) (Wellington et al 2002). It was found that Nterminal mhtt forms aggregates in the nucleus and the cytoplasm, whereas full-length mhtt is diffuse in the cytoplasm of brain cells (DiFiglia et al 1997; Sharp et al 1995). The structure of the N-terminal fragments arises from the inherent protein misfolding conferred by the polyQ expansions and the resulting pathology is still being explored. 
Although it has been difficult to define the precise role of huntingtin, its role in embryonic development has been demonstrated. After the discovery of the HD gene it was shown that a complete knockout of the gene is embryonically lethal (Duyao et al 1995). Mutant huntingtin is not entirely dysfunctional, since it can rescue the embryonic lethal phenotype seen in the huntingtin-null knockout mice (Dragatsis et al 1998).

\section{Pathology of Huntington's Disease}

Although wild-type (WT) and mutated huntingtin protein is ubiquitously expressed in many neuronal subtypes, the medium spiny neurons (MSN) of the striatum and to a lesser extent, the pyramidal neurons of the cortex are more vulnerable to degeneration, thus contributing to the clinical symptoms of the disease. Although there is widespread brain atrophy from cell loss, the cortex and striatum are most heavily affected. The striatal atrophy leads to enlargement of the lateral ventricles. Since MSNs encompass $90 \%$ of neurons in the striatum, there is a hallmark degeneration of this region of the basal ganglia with accompanying pathological changes in the thalamus and subthalamic nucleus (Hedreen et al 1991; Vonsattel \& DiFiglia 1998). Gliosis and atrophy are also seen in the substantia nigra pars reticulata. The striatum receives a large glutamatergic and trophic input from the cortex, and this connection can serve as a possible contributor to the resulting pathology. In addition to the changes in the striatum there is atrophy of the cortex and thalamus in late stages of the disease (Vonsattel \& DiFiglia 1998).

Within the striatum, HD differentially affects subpopulations of neurons, with projection neurons preferentially being lost rather than interneurons (Albin et al 1990; Difiglia 1990). Studies have shown early in the disease process that projection neurons that contain both enkephalin (ENK) and gamma-aminobutyric acid (GABA) are lost more rapidly than those that contain substance P (SP) and GABA (Deng et al 2004). The significance of this observation is enkephalin/GABA-containing neurons project to the external globus pallidus (GPe) and constitute the striatal part of the indirect pathway, whose normal activation suppresses unwanted movement. In early HD, thus, the function of the indirect pathway is predominantly disrupted, and basal ganglia circuitry models predict an overall increase in unwanted movement, manifested as chorea. This finding provides an anatomical substrate for the increased adventitious movement that is the hallmark of HD (Albin et al 1992; Deng et al 2004; Reiner et al 1988). The substance $\mathrm{P} / \mathrm{GABA}$-containing striatal neurons project to the internal globus pallidus and the substantia nigra, and thus constitute the striatal part of the direct pathway, whose activation promotes planned, appropriate movement. In later stages of adult HD, both populations of striatal projection neurons are affected (Reiner et al 1988), and both akinesia predominates.

Huntington's disease is also characterized by the presence of neuronal intranuclear inclusions (NIIs) in striatal and cortical neurons (DiFiglia et al 1997). These aggregates consist of the $\mathrm{N}$-terminal fragments of mhtt and appear early in the disease process, often before other phenotypes (Vonsattel \& DiFiglia 1998). It is the cleavage of 
the mhtt $\mathrm{N}$-terminals that promote this aggregation and it is brought about by activation of proapoptotic caspases (Wellington et al 2002). NIIs are also present in several transgenic HD mouse lines with a similar appearance before behavioral phenotypes. It was found that N-terminal htt fragments expressed in transgenic animals or cultured cells are more toxic than full-length htt (Davies et al 1997; Hodgson et al 1999; Schilling et al 1999). It is still unresolved if the aggregates are the cause of clinical symptoms or are the result of a protective mechanism that sequesters mutant protein.

\section{Pathogenesis of Huntington's Disease}

Since the gene has been discovered, there has been intense effort to find out why the predominant pathology of HD by mhtt is limited to the brain and particularly affects striatal neurons. One theory is that death in neurons occurs through apoptosis, that is, activation of a programmed cell death pathway triggered by mitochondrial dysfunction. There is evidence that indicates that WT htt triggers molecular events that lead to increased cell survival. Such pro-survival mechanisms include the inhibition of procaspase 9 and, and a pro-apoptotic protein, huntingtin-interacting protein 1, by WT htt (Gervais et al 2002; Rigamonti et al 2000; Zhang et al 2006). Mitochondria play a role in the process of caspase activation and apoptosis. 3-nitroproprionic acid (3-NP) is an irreversible inhibitor of mitochondrial complex II, and causes apoptotic neuronal death through the release of cytochrome-c with consequent activation of caspases (Almeida et al 2006). Injection of 3-NP or malonate (a reversible mitochondrial complex II inhibitor) into the striatum leads to neuronal loss resembling that in HD (Beal et al 1993; Shear et al 1998). In human post mortem analysis, DNA fragmentation characteristic of apoptosis has been described in HD brain (Thomas et al 1995). Although these findings are promising for understanding HD pathogenesis, it is not yet clear if apoptosis is the principle event responsible for striatal cell death in HD.

Theories of HD pathogenesis also implicate excitotoxicity or energetic dysfunction. Glutamate is responsible for excitatory synaptic transmission in the central nervous system by acting upon three classes of ionotropic receptors: N-methyl-Daspartate (NMDA), $\alpha$-amino-3-hydroxy-5-methyl-4-isoxazolepropionate (AMPA), and kainate receptors. The selective loss of striatal projection neurons could come about due to overactivity of the vast glutamatergic input from the cerebral cortex, while striatal interneurons, which are less affected in HD, have fewer excitatory inputs. MSNs showed an increased NMDA current density and swelling compared to interneurons in striatal slices from HD mutant mice (Cepeda et al 2001). This suggests that continuous exposure of ionotropic NMDA receptors to glutamate can be excitotoxic in HD and leave striatal neurons vulnerable to damage. The NMDA receptor is important in synaptic plasticity as well as cell death due to its voltage dependent magnesium block and high calcium permeability (Bliss \& Collingridge 1993). Excessive stimulation causes an influx of calcium ions, leading to activation of enzymes that degrade proteins and cause cell death (Berliocchi et al 2005). Striatal NMDA receptor function is enhanced in the R6/2 and other transgenic HD models (Cepeda et al 2001; Laforet et al 2001; Levine et al 1999). Presynaptic group II metabotropic glutamate (mGluR2 and mGluR3) receptors located at 
the corticostriatal terminals are capable of regulating the release of glutamate (Calabresi et al 1996; Cepeda et al 2001). The mGluR2/mGluR3 receptors belong to heterogeneous family of glutamate receptors that are linked to GTP-binding proteins, and this particular class is negatively coupled to cyclic AMP production (Nakanishi 1992). It is known that mGluR2 receptors are located presynaptically and can negatively modulate glutamate release (Battaglia et al 1997). Activation of these receptors by an agonist reduces excitatory-post-synaptic-potentials (EPSPs) in striatal neurons (Calabresi et al 1996), thus dampening the effect of glutamate release from corticostriatal terminals. Any alteration of these receptors could lead to a pathological increase of glutamate release, and it was discovered that there is a decreased expression of mGluR2 and mGluR3 receptors in the transgenic HD mouse R6/2 (Cha et al 1998).

Excitotoxicity can also come about due to decreased clearance of extracellular glutamate from the synaptic cleft. This uptake of glutamate is carried out via the EAAT2 transporter by glial cells. There is a decrease of this transporter and the enzyme glutamine synthetase in HD mice (Lievens et al 2001). Glutamine synthetase is primarily found in astrocytes in the brain and aids in diminishing excitoxicity of neurons by uptake of excessive glutamate (Suarez et al 2002). Mutant huntingtin also is present in glial cells, and it was shown that there is an increase neuronal vulnerability among neurons cultured with astrocytes expressing mhtt as opposed to neurons cultured with astrocytes expressing wild-type htt (Shin et al 2005).

Normal huntingtin has been linked to brain derived neurotrophic factor (BDNF) via different mechanisms involving BDNF transcription and vesicular transport. This protein is important for the survival of striatal neurons (Widmer \& Hefti 1994). BDNF is co-localized with huntingtin in cortical neurons that project to the striatum and most striatal BDNF is produced in the cerebral cortex (Altar et al 1997; Baquet et al 2004; Fusco et al 2003). Wild-type huntingtin promotes the vesicular transport of BDNF along microtubules via huntingtin-associated-protein 1(HAP1) (Gauthier et al 2004), and BDNF transport to striatum is thus impaired in HD. Evidence for pathogenesis stemming from diminished BDNF production in the cortex and transport to striatum comes from multiple HD mice. Reduced cortical mRNA levels for BDNF and reduced cortical and striatal protein levels are found in YAC mice (Zuccato et al 2001), R6/2 mice (Zuccato et al 2005), and mutant huntingtin knock-in mice (Gines et al 2003). These data indicate that decreased BDNF transcription occurs in HD. It was shown that mhtt reduces the transcription of several exons of BDNF in the cortex due to both loss of wild type huntingtin and a toxicity of the mutant protein (Zuccato et al 2001; Zuccato et al 2005). Baquet et al showed behavioral and striatal changes with a cortical BDNF knock-out mouse model that paralleled the neurological dysfunction seen in R6/2 mice (Baquet et al 2004).

\section{Therapies in Huntington's Disease}

It is challenging to perform therapeutic trials in HD patients for a variety of reasons. Since there is a low prevalence of the disease, recruitment of a sufficient 
number of patients is difficult. The disease has a slow progression so potential drugs that might have a benefit require a long follow up. It is important that all original therapies are tested in cell cultures and animal models before being moving to clinical trials. Although it is not known what causes death of striatal neurons and sickness of cortical neurons in $\mathrm{HD}$ as discussed in previous sections, there are novel ideas being tested with various kinds of therapies. The ability to screen for new agents has advanced rapidly with understanding of HD pathogenesis. Among methodologies, yeast and cell culture models are inexpensive and lend themselves to rapid testing. Studies typically begin by screening compounds on cultured neurons for efficacy. High throughput assays screen for molecules that target specific pathways (such as huntingtin aggregation in vitro) or that block cell toxicity (Apostol et al 2003; Murphy et al 2000). Potential therapeutic agents are being identified in studies of excitotoxic and mitochondrial toxin models of HD. A strategy is to move these compounds to a more realistic model than cell cultures and a number of agents have been shown to be effective in transgenic mouse models of HD. In light of the strong evidence of excitotoxic damage in HD as discussed earlier, an in vivo model offers a better choice to test ideas about excitotoxicity.

A valid in vivo model should show a measureable progression of pathology replicating mid- to late-life onset of motor impairment. The R6/2 HD mouse is a good in vivo model because it replicates several phenotypes and neuropathologies seen in humans, including a progressive motor and cognitive impairment (Bolivar et al 2003; Carter et al 1999; Murphy et al 2000), ubiquitinated nuclear and cytoplasmic inclusions of mhtt (Davies et al 1997; Li et al 1999), and decreased brain and striatum size (Mangiarini et al 1996). In a microarray study of postmortem human HD cases, it was found that R6/2 mice reproduce the transcriptomic changes of human HD (Kuhn et al 2007). This animal model has been shown to have a decrease in cortical mGluR $2 / 3$, which is capable of contributing to excitotoxicity (Cha et al 1998). As discussed earlier, an increased NMDA receptor-mediated current could lead to excitotoxic effects and activation of a presynaptic cortical autoreceptor could limit this effect. R6/2 mice were also shown to have a decrease in measured ENK-immunoreactive fiber intensity in GP when compared to wild type mice at 12 weeks of age (Sun et al 2002). This may be indicative of an early stage of striatal neuron degeneration in adult onset HD (Reiner et al 1988; Sapp et al 1995). Sun et al found elevated SP-immunoreactive fiber intensity in $\mathrm{SN}$ of R6/2 at 12 weeks of age, which counters that found in adult-onset HD. This could reflect a dysfunction in release of SP by striatonigral neurons (Sun et al 2002). Volume changes of brain regions are also reflected in the transgenic models. There is a $41 \%$ striatal volume reduction and total brain reduction of $44 \%$ of R6/2 mice at 90 days (Stack et al 2005). This is accompanied by a $26 \%$ striatal neuron loss. Preliminary studies with the R6/2 transgenic mouse showed that this model develops several progressive motor pathologies (Mangiarini et al 1996). These included progressive hypoactivity, resting tremors, abrupt and shuddering movements, epileptic seizures, foot clasping and dyskinesia of hindlimbs upon tail suspension (Carter et al 1999).

Precise and definable measured patterns of movement and locomotion are critical endpoints in assays with HD mice. Open field assays test many motor and behavioral endpoints, and many of these traits are affected in HD. Since the pathology exists in the 
basal ganglia, open-field testing is beneficial for evaluating the complexity of exploratory behavior. The Golani and Drai automated open field task allows rapid and automatic measurement of many aspects of locomotion (Drai \& Golani 2001). These measured parameters include bursts of locomotion called progression segments and pauses termed lingering episodes. The velocities of the progression segments and the number of stops are calculated for an open field session. The use of SEE (Software for the Exploration of Exploration) allows the parameters to be isolated and quantified. Measured endpoints reflect processes of navigation, motivation, locomotion, spatial memory and learning (Drai \& Golani 2001). Rotarod is another assay that measures coordination and balance. R6/2 mice have difficulty maintaining balance on the device at 5-6 weeks of age (Carter et al 1999; Luesse et al 2001). One caveat of the test is that there is a cerebellar component to completing the task (Crawley 1999). Other endpoints to measure that reflect overall health are weight loss and lifespan. When compared to wild type (WT) littermates, the R6/2 transgenic mice show a decline in body weight after 10 weeks of age. Lifespan for this model is 10-13 weeks (Carter et al 1999; Mangiarini et al 1996). 


\section{CHAPTER 2. RESEARCH OBJECTIVES AND SPECIFIC AIMS}

Excessive glutamate release from cortical terminals in striatum can result in a pattern of injury that is similar to the one seen in Huntington's disease. Previous work was shown that the R6/2 Huntington's disease (HD) mouse model has an enhanced striatal NMDA receptor-mediated current (Cepeda et al 2001). The increased activation of striatal neurons can result in an excitotoxic loss of medium spiny neurons in the striatum. One method to curtail this increase is the use of an mGluR2/3 receptor agonist. Activation of this receptor, which is localized to cortical terminals in striatum, decreases the release of glutamate and thus dampens excitotoxic effects (Calabresi et al 1996).

An inviting drug for HD therapy is an mGluR2/3 agonist. There is evidence that mGluR2/3 agonists have significant neuroprotective potential. Administration of LY379268 (a mGluR2 agonist) was shown to limit ischemic and hypoxic injury (Bond et al 1999; Kingston et al 1999). Excitotoxic injury involves the same caspases that are involved in HD and thus lends credence to LY379268 being a good choice of experimental therapeutics to limit neuronal death in HD. In a previous study, LY379268 showed a benefit on lifespan but not rotarod performance in R6/2 HD transgenic mice (Schiefer et al 2004). While these results are promising, the study was limited in several ways. The drug was dosed at $1.2 \mathrm{mg} / \mathrm{kg}$ dissolved in water, and then given orally to the subjects via an applicator tube in the upper esophagus. A question can be raised if maximal benefit can be achieved from LY379268 from such a low dose. The neuroprotective effects of LY379268 were seen in other studies with dosings much higher than $1.2 \mathrm{mg} / \mathrm{kg}$ as used by Schiefer et al (Bond et al 1999; Cai et al 1999; Kingston et al 1999). The study used NIIs as a histological endpoint, and found no differences in distribution and size of NIIs among R6/2 mice given LY379268 or a placebo. The authors used NIIs as the only morphological measure of pathological changes in HD mice, while there are other known phenotypical changes that can be considered, such as distinct volume changes and neuronal abundance. A complete study should include measurements of these other morphological changes. Behavioral testing in the Schiefer study included an open field assay which showed a decline in hyperactive spontaneous locomotion with LY379268 administration as compared to control mice. It is possible that more improvement could be observed with a higher dose of the drug and more sophisticated behavioral testing. There are many approaches that measure locomotion and motor skills more robustly than used by Schiefer et al (2005). A study is needed showing the efficacy of a higher dose of LY379268 on behavioral endpoints and numerous morphological pathologies. Some of the treatments that target excitoxicity and oxidative stress which have shown to be beneficial in transgenic mouse models may improve some of the symptoms in HD patients and it is therefore logical to pursue therapies aimed in this direction. A more detailed exploration of the ability of LY379268 to reverse the behavioral, motor and histological abnormalities in the R6/2 is carried out with this series of experiments. All of the fixed-tissue histological and morphometric data collection was completed by me, while the behavioral work and in situ hybridization (ISH) was carried out by other personnel in the lab, but the behavioral and ISH results are 
presented in this thesis because they are a critical adjunct to the histological data in giving a complete picture of potential therapeutic outcomes with LY379268.

The aims of the project were:

- Aim 1: To test the hypothesis that LY379268 can normalize known changes in histological endpoints.

- Aim 2: To test the hypothesis that LY3979268 can normalize the lifespan, body weight, behavioral and motor abnormalities seen in the R6/2 mouse model. 


\section{CHAPTER 3. EXPERIMENTAL PROCEDURES}

\section{Subjects}

R6/2 mice, which bear a transgene for the 5' end of the human HD gene carrying about $150 \mathrm{CAG}$ repeats and including the promoter region, were obtained from Jackson Laboratories (Bar Harbor, ME). A colony was maintained by breeding R6/2 mice with CBA X C57BL/6 F1 (B6CBAF1) mice, thereby obtaining offspring that were hemizygous for the transgene and wild-type littermates. Mice were genotyped and CAG repeat length determined using a PCR-based amplification method (Sun et al 2002). R6/2 and WT mice were randomly assigned to either control treatment with vehicle or treatment with LY379268. Daily subcutaneous injections of LY $(20 \mathrm{mg} / \mathrm{kg})$ began after genotyping at PND21. Thirty-four mice were used in the four treatment groups for the fixed-tissue histological analysis. Seventy-seven mice were used in the four treatment groups for behavioral analysis.

\section{Tissue Fixation}

Under deep anesthesia (avertin; $0.2 \mathrm{cc} / \mathrm{g}$ body weight), transgenic R6/2 mice and wild-type mice were perfused transcardially with $60 \mathrm{ml}$ of $6 \%$ dextran in $0.1 \mathrm{M}$ sodium phosphate buffer at pH 7.4 (PB), followed by $200 \mathrm{ml}$ of $4 \%$ paraformaldehyde, $0.1 \mathrm{M}$ lysine- $0.1 \mathrm{M}$ sodium periodate in $0.1 \mathrm{M} \mathrm{PB}$ (PLP). The brains were removed and stored for at least 24 hours in a $20 \%$ sucrose $/ 10 \%$ glycerol solution at $4{ }^{\circ} \mathrm{C}$. The fixed brains were sectioned frozen on a sliding microtome in the transverse plane at $35 \mu \mathrm{m}$. Each brain was collected as 12 separate series in $0.1 \mathrm{M} \mathrm{PB} 0.02 \%$ sodium azide and stored until processed for immunohistochemistry. A series of sections from the brain of each mouse was stained for cresyl violet to study normal brain histology.

\section{Immunohistochemistry}

Immunohistochemical labeling was carried out to characterize abnormalities in cortex or striatum. Immunohistochemical single-labeling for ubiquitin, to visualize NIIs in R6/2 mice, was carried out using a peroxidase-antiperoxidase (PAP) procedure described previously (Anderson \& Reiner 1990). Immunolabeling was also used for NeuN for neuron labeling, substance P (SP) for SP+ striatal projection systems, and enkephalin $(\mathrm{ENK})$ for ENK+ striatal projection systems. To carry out immunohistochemical labeling, sections were incubated for 24 hours at room temperature in primary antiserum diluted 1:2000-1:5,000 with $0.3 \%$ Triton $X-100 / 0.02 \%$ sodium azide/0.1 M PB (PBX). Sections were then rinsed and incubated in donkey anti-mouse IgG or anti-rabbit IgG (depending on the primary antiserum) diluted 1:50 in PBX, followed by incubation in the appropriate mouse or rabbit PAP complex diluted 1:200 in $\mathrm{PBX}$, with each incubation at room temperature for 1 hour. The sections were rinsed between secondary and PAP incubations in three 5-minute washes of PB. Subsequent to 
the PAP incubation, the sections were rinsed with three to six 10-minute washes in $0.1 \mathrm{M}$ $\mathrm{PB}$, and a peroxidase reaction using diaminobenzidine tetrahydrochloride (DAB) was carried out. Sections were incubated in $5 \mathrm{ml}$ of $0.05 \mathrm{M}$ imidazole $/ 0.05 \mathrm{M}$ cacodylate buffer ( $\mathrm{pH}$ 7.2) containing $5 \mathrm{mg}$ DAB for 10 minutes and then incubated for an additional 10 minutes after adding $20 \mu 1$ of $3 \%$ hydrogen peroxide, with continuous agitation throughout. Sections were then washed in distilled water, placed in $0.1 \mathrm{M} \mathrm{PB}$, mounted onto gelatin-coated slides, dried, dehydrated, and cover slipped with Permount.

\section{Microscopic Analysis}

\section{NII Frequency and Size}

Sections immunolabeled for ubiquitin from R6/2 mice and wild-type mice were analyzed for NII size and frequency. This analysis was carried out blinded to the treatment groups. For each mouse, images of primary motor cortex and striatum were captured from each of three sections, one at the level of rostral striatum, one at the level of the midstriatum, and one just behind the anterior commissure using a $40 \mathrm{X}$ objective on an Olympus BH-2 microscope, a Spot camera, and a Mac computer. These images were used to determine NII frequency (number of NIIs per field), size, and percent of the field occupied by NIIs for the cortex and striatum. Three adjacent images of primary motor cortex were captured and analyzed for each level, with analysis performed separately on layers II/III, V, and VI. For striatum, images of central, dorsomedial, ventromedial, dorsolateral, and ventrolateral striatum were analyzed for each level. Frequency and percent of the field occupied by NIIs was determined by thresholding NIIs using Image-J software (from U.S. National Institutes of Health, available at http://rsb.info.hih.gov/nihimage). NII size (i.e., diameter) was also measured for cortex and striatum using Image$\mathrm{J}$. Artifacts in the images were removed prior to thresholding, and the size of the thresholded NIIs was assessed using the Particle Measurement function of NIH Image.

\section{Volume Measurements}

Blinded examination of sections through the rostral telencephalon suggested lateral ventricular expansion and striatal shrinkage in the R6/2 brains. To evaluate this quantitatively, image analysis was blindly carried out to determine the volume of the telencephalon, cerebral cortex, lateral ventricle, striatum, and septum for the rostral telencephalon (i.e., from the end of the olfactory bulb to the level just behind the anterior commissure). For each mouse an image of each section in a one-in-six series from the rostral telencephalic pole to the level of just behind the anterior commissure, at which levels the lateral ventricles are narrow in normal mice, was captured at high resolution (4800 dpi) using a Epson scanner. NIH Image was used to measure the areas occupied by the entire telencephalon, the cerebral cortex, the lateral ventricles, the striatum, and the septa on each side of the brain. The cerebral cortex was measured from the midline to the rhinal fissure from pial surface to external capsule. The striatum was defined by the 
contours of the external capsule and globus pallidus, while the septum was defined as the region between the corpus callosum and a horizontal line connecting the ventral tips of the ventral horns of the lateral ventricles. Section thickness and spacing were used to determine the volume of each structure from the areal measurements in the cross-section. Because brain size is correlated with brain size, comparisons of absolute brain size of the above individual brain areas between R6/2 mice and WT mice is confounded by the smaller size of R6/2 mice. To correct for this, we present the volume data divided by body weight raised to the 0.66 power (the allometric scaling exponent for the relation of body size to brain size) (Lande, 1979).

\section{Image Analysis of Immunolabeling in Striatal Target Areas}

To assess injury to the neurons of origin of the striatal projection systems, quantitative computer-assisted image analysis was carried out on immunolabeled striatal terminals in each of the main striatal projection targets, blindly to treatment group. For these studies, the areal extent and immunolabeling intensity of the ENK+ fiber plexus in the GPe and the SP+ fiber plexuses in the GPi and substantia nigra were quantified. For GPe, its ENK+ plexus in the 2-4 sections spanning its rostrocaudal extent were captured bilaterally. For GPi, images of the entire GPi from 1-2 sections spanning its rostrocaudal extent were bilaterally captured for analysis. For substantia nigra, the entire nigra in 2-4 sections spanning its rostrocaudal extent were captured and analyzed bilaterally. The immunolabeled fibers in these striatal target areas were highlighted and the area occupied by them and their labeling intensity determined using the thresholding and optical density measuring capabilities of Image-J. To correct for slight variations in image intensity stemming from variations in lighting during image capture and/or from variations in the staining protocol, the background intensity of the captured images was standardized to a value of 100 on the 0-255 gray scale employed by the Image program using the image editing capabilities of this program. The region of each image used to set the background intensity was an area of unlabeled white matter within the field of view. For GPe and GPi the external capsule was used for optical density standardization, while for images of the substantia nigra the cerebral peduncle was used. Fiber abundance for a given structure in a given case was expressed as the mean percent of the structure occupied by labeled fibers for all measurements for that case. Fiber abundance for each target area for each HD case was then expressed as a percent of control.

\section{Stereology}

Stereological neuron counts were carried out blindly to the treatment groups of the mice. A one-in-six series immunolabeled for NeuN from just behind the olfactory bulb to the level of the anterior commissure were used for striatal and cortex neuron analysis. Landmarks were as those noted above for the volume measurements. Unbiased stereological counts of striatal and cortical neurons were obtained by using Neurolucida Stereo Investigator software (Micro-Brightfield, Colchester, VT). The dissector counting method was used where counting frames are taken from a random series of evenly spaced 
sections. These counting frames are chosen by the software within predefined areas used for demarcating the volumes of the striatum and cortex.

\section{Behavioral Analysis}

\section{Rotarod}

Rotarod was performed at the same time of the day to be consistent with the diurnal activity phase. During the training period, each mouse was placed on an accelerating rotarod starting at $0 \mathrm{rpm}$ and accelerating gradually up to $30 \mathrm{rpm}$ at 240 seconds. This maximum velocity was maintained for an additional 120 seconds. Mice received four training trials during the first session, by which time a steady baseline level of performance was achieved. Rotarod sessions were run twice a week, with $\mathrm{x}$ trials per session after the first four-trial training session. The trial was considered over when a mouse fell off the rotarod or when it stayed on the rod for a maximum of 360 seconds. The latency to fall off was recorded and used in subsequent analysis.

\section{Open Field}

A circular open field arena with a diameter of $180 \mathrm{~cm}$ and $60 \mathrm{~cm}$ high walls was used to evaluate locomotor activity of the mice. Each mouse was placed in the arena for a 30-minute trial once a week. A mouse was placed near the wall and its behavior in the arena was recorded throughout the session by a stationary video camera whose lens covered the whole cylinder field. The locomotor path traversed by the mouse was recorded by an automated tracking system using Ethovision, and analyzed by SEE software. The SEE software extracted a number of locomotor parameters of interest, as presented here, including length and duration of locomotor bursts called progression segments, time spent locomoting (activity), duration and time spent lingering, speed and acceleration during progression segments, and spatial distribution of progression segments.

\section{Statistical Analysis}

The body weight, rotarod and open field data were analyzed statistically using SAS software and a mixed model ANOVA, considering genotype, drug, gender and their interactions in the analysis. Data for the immunohistochemical studies were analyzed statistically by ANOVA followed by Fisher PLSD individual group comparisons, reciprocal transforming data as need to normalize distributions. 


\section{CHAPTER 4. RESULTS}

\section{Histological Studies of Fixed Tissue}

The effects of LY379268 were blindly analyzed on telencephalic, cortical, striatal and lateral ventricular volumes. Other parameters included neuron abundance in cortex and striatum, neurochemical integrity of striatal projections systems, and NII size and frequency. The completed analysis included 8-10 LY-treated R6/2 mice (average CAG = 119.1), 9-10 vehicle-treated R6/2 mice (average CAG = 118.3), 9-10 LY-treated WT mice, and 8-11 vehicle-treated WT mice.

\section{Volumetric Analysis}

Volumes were measured blindly from the end of the olfactory bulb to the level behind the anterior commissure. The R6/2 mice had a smaller body mass. To correct for the impact of this on brain size, and determine if the R6/2 genotype and/or the drug treatment affected brain part size, brain volumes were expressed using an allometric correction. Brain and body weights are related by the following allometric equation "brain $=\kappa\left(\right.$ body) ${ }^{\alpha}$ " where $\alpha=0.67$ (Lande, 1979). Thus, dividing brain size by body weight raised to the 0.67 power corrects for the impact of body size variation on brain size.

As shown in Table 1, telencephalic volumes differed among the groups, but were similar between the R6/2 vehicle-treated and WT vehicle-treated mice. This data set shows that WT-LY treated group telencephalic volume was greater $\left(69.1 \mathrm{~mm}^{2}\right)$ than in any other group, but the telencephalic size reflected a larger body size. The allometric correction shows that this increase is not significant since corrected telencephalic volume is $104.9 \%$ of that in WT-V. The average measured volumes of cortex in R6/2 mice were slightly smaller than in WT mice, but the difference was not significant. Treatment with the LY compound did not produce a significant effect on cortex volume in either the WT or R6/2 mice compared to the vehicle-treated mice. Volume of the striatum in R6/2-LY mice was, however, less than in vehicle-treated WT mice. There was a significant and large increase in ventricular volume in both R6/2 mice groups in contrast to WT mice. Treatment with LY379268 did not cause a significant decrease in ventricular volume in the R6/2 mice compared to the vehicle-treated R6/2 mice. These various results are shown in Table 1.

\section{Neuron Counts}

The neuron abundance for cortex and striatum was significantly less in the R6/2 vehicle as compared to the WT vehicle treated mice ( $85 \%$ and $83.7 \%$, respectively). Stereological neuron counts also showed significantly fewer neurons in vehicle-treated R6/2 mice than LY-treated R6/2 mice in cortex and striatum. Cortical and striatal neuron 
Table 1. Volumetric Analysis

\begin{tabular}{|c|c|c|c|c|c|c|c|c|c|}
\hline $\begin{array}{l}\text { Mouse Treatment } \\
\text { Groups }\end{array}$ & $\begin{array}{l}\text { \# of } \\
\text { Mice }\end{array}$ & $\begin{array}{l}\text { Telen } \\
\text { Volume in } \\
\mathrm{mm}^{2}\end{array}$ & $\begin{array}{l}\text { Body } \\
\text { Weight in } \\
\text { Grams }\end{array}$ & $\begin{array}{l}\text { Telen } \\
\text { Volume / } \\
\text { Body } \\
\text { Weight }\end{array}$ & $\begin{array}{l}\text { Telen } \\
\text { Volume / } \\
\text { (Weight) }^{.67}\end{array}$ & $\begin{array}{l}\text { Cortex } \\
\text { Volume / } \\
\text { (Weight) }^{.67}\end{array}$ & $\begin{array}{l}\text { Striatum } \\
\text { Volume / } \\
\text { (Weight) }^{67}\end{array}$ & $\begin{array}{l}\text { Ventricle } \\
\text { Volume / } \\
\text { (Weight) }^{.67}\end{array}$ & $\begin{array}{l}\text { Septum } \\
\text { Volume / } \\
\text { (Weight) }^{.67}\end{array}$ \\
\hline WT - Vehicle & 8 & 62.0 & 21.8 & 2.92 & $100 \%$ & $100 \%$ & $100 \%$ & $100 \%$ & $100 \%$ \\
\hline WT - LY379268 & 9 & 69.1 & 23.8 & 2.94 & $104.9 \%$ & $107.8 \%$ & $100.7 \%$ & $114.5 \%$ & $109.6 \%$ \\
\hline R6/2-Vehicle & 9 & 62.2 & 22.3 & 2.82 & $99.4 \%$ & $96.9 \%$ & $99.6 \%$ & $250.9 \% * \wedge$ & $106.5 \%$ \\
\hline R6/2 - LY379268 & & $60.6^{\wedge}$ & 20.7 & 2.95 & $99.1 \%$ & $92.8 \%$ & $87.9 \%$ & $236.7 \% * \wedge$ & $99.7 \%$ \\
\hline
\end{tabular}

Note: *significantly different from WT-Vehicle; ^^significantly different from WT-LY379268 
abundance, however, did not differ between the WT mice and the LY-treated R6/2 mice. Thus, there was about a $20 \%$ decrease in neuron abundance in striatum and cortex of R6/2-vehicle mice, which was rescued in the R6/2 mice by daily injections of $20 \mathrm{mg} / \mathrm{kg}$ of LY379268 (Table 2).

\section{Striatal Projection Systems}

Immunohistochemical analysis of striatal projection neurons were measured by thresholding of the terminals projecting to the external pallidal segment (GPe) for enkephalin, internal pallidal segment (GPi) or substantia nigra (SN) for substance P. This labeling technique allows measurement of peptide abundance within these striatal targets. A benefit of the LY drug on R6/2 mice was seen in the SP projection neurons.

\section{Striatonigral}

As shown in Table 3, the percentage of nigra covered by SP fibers in R6/2-vehicle mice is significantly larger than in WT-V mice (39\%) or WT-LY mice $(42.4 \%)$. Daily injections of LY379628 reduced the percentage of nigra covered by SP fibers so it was not significantly different from the WT groups, but was less than in R6/2-V mice $(21.9 \%$ lower). The intensity of SP labeled fibers in nigra is significantly elevated in the LY-WT group and the two R6/2 groups compared to the Vehicle-WT group. The intensity elevation in the WT-LY group indicates that the LY drug did affect SP+ striatonigral neurons in WT mice. Immunolabeling intensity is a reflection of the amount of peptide present, and in this case it is likely it reflects a failure of release, in both the WT-LY mice as well as the R6/2 mice groups, as explained in the Discussion. The pattern of SP immunolabeling in these mouse groups is illustrated in Figure 1. Note that in the R6/2vehicle mice $\mathrm{SP}+$ fibers cover the entire nigra, but in both the WT-Vehicle and R6/2-LY mice a lateral part of the nigra is notably poor in SP.

\section{Striato-GPi}

As shown in Table 4, $\mathrm{SP}+$ fiber coverage was significantly greater in striato-GPi of R6/2-vehicle mice ( $106 \%$ of WT-V) compared to WT-LY mice ( $95.9 \%$ of WT-V), but $\mathrm{SP}+$ fiber coverage was at WT-vehicle levels in R6/2 mice treated with LY379268 $(101.6 \%$ of WT-V). This is consistent with the trend observed in striatal projection terminals in the nigra, but less dramatic. These data as well suggest that LY379268 normalizes SP+ fiber abundance in GPi in R6/2 mice. The intensity of SP labeling was significantly increased in striatal terminals in GPi of LY-treated WT mice (117.2\%) as compared to WT-vehicle treated mice (100\%). Thus, mGluR2/3 agonism significantly increased SP+ labeling in striato-GPi terminals in WT mice, which we interpret as diminished SP release due to diminished corticostriatal activation of striato-GPi neurons. The intensity of SP immunolabeling in striato-GPi terminals was also significantly 
Table 2. Neuron Counts

\begin{tabular}{|c|c|c|c|c|c|}
\hline \multirow[t]{2}{*}{ Group } & \multicolumn{3}{|c|}{ Number of Cortical Neuron Cortical } & \multirow{2}{*}{$\begin{array}{l}\text { Striatal Neuron } \\
\text { Count }\end{array}$} & \multirow{2}{*}{$\begin{array}{l}\text { Striatal Neuron } \\
\text { as } \% \mathrm{WT}\end{array}$} \\
\hline & Mice & Count & $\begin{array}{l}\text { Neuron as } \% \\
\text { WT }\end{array}$ & & \\
\hline $\begin{array}{l}\text { WT - } \\
\text { Combined }\end{array}$ & 21 & 448,700 & $100 \%$ & 231,157 & $100 \%$ \\
\hline $\begin{array}{l}\text { R6/2- } \\
\text { Vehicle }\end{array}$ & 10 & $381,411.3^{*}$ & $85 \%$ & $193,588.2 *$ & $83.7 \%$ \\
\hline $\begin{array}{l}\text { R6/2- } \\
\text { LY379268 }\end{array}$ & 10 & $461,906.5 \#$ & $103.4 \%$ & $241,399.8 \#$ & $104.4 \%$ \\
\hline
\end{tabular}

Note: *significantly different from WT; \#significantly different from R6/2-Vehicle 
Table 3. Effect of LY379268 on Striatal Projection Neurons in Nigra of R6/2 Mice

\begin{tabular}{lllll}
\hline $\begin{array}{l}\text { Mouse } \\
\text { Groups }\end{array}$ & $\begin{array}{l}\text { \# of } \\
\text { Mice }\end{array}$ & $\begin{array}{l}\text { Mean } \\
\text { Repeat } \\
\text { Length }\end{array}$ & $\begin{array}{l}\text { \% of Nigra Covered by } \\
\text { SP+ Fibers from Direct } \\
\text { Pathway Neurons }\end{array}$ & $\begin{array}{l}\text { Intensity of SP+ Fibers in } \\
\text { Nigra Arising from Direct } \\
\text { Pathway Neurons }\end{array}$ \\
\hline $\begin{array}{l}\text { WT }- \\
\text { Vehicle }\end{array}$ & 8 & N/A & $100 \%$ & $100 \%$ \\
$\begin{array}{l}\text { WT }- \\
\text { LY379268 }\end{array}$ & 8 & N/A & $96.6 \%$ & $114.8 \% *$ \\
$\begin{array}{l}\text { R6/2 }- \\
\text { Vehicle }\end{array}$ & 9 & 118.3 & $139.0 \% * \wedge$ & $115.5 \% *$ \\
$\begin{array}{l}\text { R6/2- } \\
\text { LY379268 }\end{array}$ & 8 & 119.1 & $117.1 \% \#$ & $111.8 \% *$ \\
\hline
\end{tabular}

Note: *significantly different from WT-Vehicle; ^significantly different from WTLY379268; \#significantly different from R62-Vehicle 


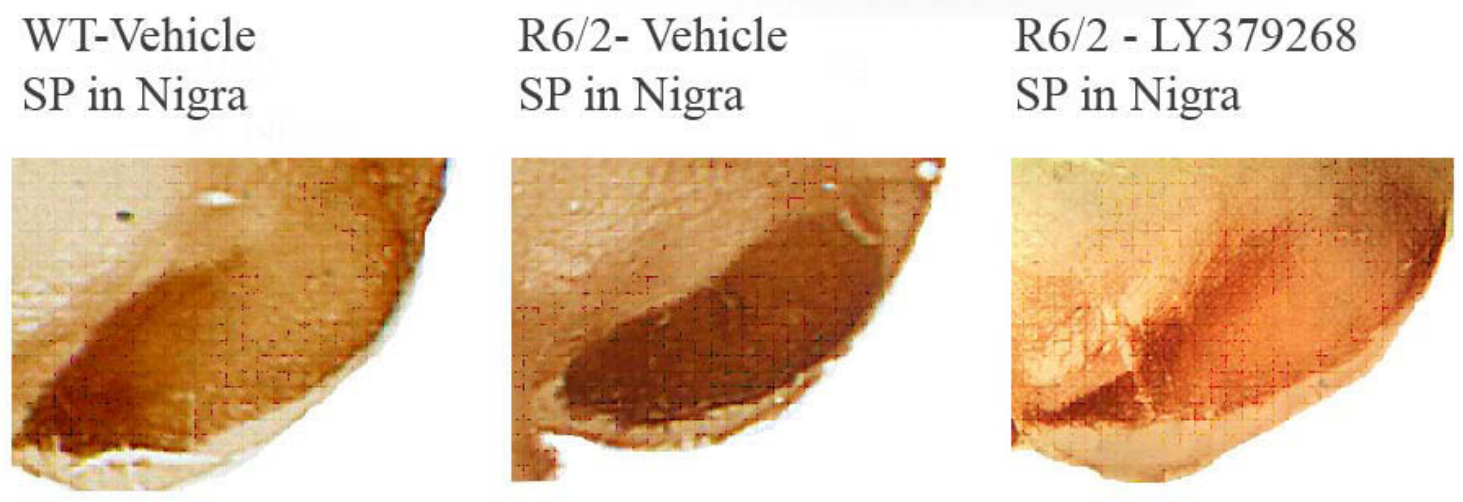

Figure 1. SP in Nigra 
Table 4. Effect of LY379268 on Striatal Projection Neurons in GPi of R6/2 Mice

\begin{tabular}{lllll}
\hline $\begin{array}{l}\text { Mouse } \\
\text { Groups }\end{array}$ & $\begin{array}{l}\text { \# of } \\
\text { Mice }\end{array}$ & $\begin{array}{l}\text { Mean } \\
\text { Repeat } \\
\text { Length }\end{array}$ & $\begin{array}{l}\text { \% of GPi Covered by } \\
\text { SP+ Fibers from Direct } \\
\text { Pathway Neurons }\end{array}$ & $\begin{array}{l}\text { Intensity of SP+ Fibers in } \\
\text { GPi Arising from Direct } \\
\text { Pathway Neurons }\end{array}$ \\
\hline $\begin{array}{l}\text { WT }- \\
\text { Vehicle }\end{array}$ & 8 & N/A & $100 \%$ & $100 \%$ \\
$\begin{array}{l}\text { WT }- \\
\text { LY379268 }\end{array}$ & 9 & N/A & $95.9 \%$ & $117.2 \% *$ \\
$\begin{array}{l}\text { R6/2 }- \\
\text { Vehicle }\end{array}$ & 9 & 118.3 & $106.0 \% \wedge$ & $122.4 \% *$ \\
$\begin{array}{l}\text { R6/2 }- \\
\text { LY379268 }\end{array}$ & 8 & 119.1 & $101.6 \%$ & $120.4 \% *$ \\
\hline
\end{tabular}

Note: *significantly different from WT-Vehicle; ^significantly different from WTLY379268 
increased in both R6/2 mice groups, which is likely to be an effect of the genotype of striato-GPi neuron activity.

\section{Striato-GPe}

Coverage of GPe with immunolabeled ENK + fibers in R6/2 - vehicle treated mice was significantly less than in WT-V mice $(92.5 \%$ of WT-V). While seemingly similarly reduced in R6/2-LY mice (93.4\%), this was not significantly different than WTV. The fiber coverage in the two WT groups was not significantly different. There were no significant differences among the four groups in ENK+ fiber intensity in GPe. Overall, these results indicate no major effect of genotype on ENK+ fibers in GPe, and no major effect of LY379268 on the ENK+ fibers in GPe in either WT or 6/2 mice. These results are shown in Table 5.

\section{Mutant Protein Aggregation}

Measurements were carried out for ubiquitin immunolabeling of NIIs in 6 LYtreated R6/2 and 9 vehicle-treated mice. Measurements of NIIs were only carried out on the R6/2 mice, as NIIs do not form in WT mice. There were no significant differences in frequency (area of field covered by NIIs) or NII size in cerebral cortex or striatum between vehicle-treated and LY379268-treated R6/2 mice. For example, the percent of the field covered by NIIs was $1.27 \%$ in R6/2-V mice and $0.82 \%$ in R6/2-LY mice. Similarly, the percent of the field covered by NIIs in the striatum was $0.63 \%$ for R6/2 mice receiving LY379268 and $0.51 \%$ in vehicle treated R6/2 mice. The average NII size in the cortex of R6/2-LY was $2.09 \mu \mathrm{m}$, and R6/2-Vehicle in $2.06 \mu \mathrm{m}$, which is not significant. Similarly, NII size in the striatum of R6/2-LY mice was $1.54 \mu \mathrm{m}$, and in striatum of R6/2-Vehicle mice was $1.61 \mu \mathrm{m}$. While Schiefer et al (2004) reported that NII size in R6/2 mouse cortex was increased $20 \%$ using the same agonist, the current study demonstrated no evidence that LY379268 affects nuclear aggregate formation.

\section{Histological Studies of Unfixed Tissue}

The in situ hybridization (ISH) data was completed by Hong Bing Wang and is presented here for completeness. Tissue was analyzed that had been fresh-frozen ISH processed using digoxigenin detection with riboprobes for ENK and SP ISH from 10 WT-vehicle mice, 11 WT-LY mice, 10 R6/2-vehicle mice, and 11 R6/2-LY mice. All mice were 10 weeks old, and the labeling was analyzed using computer-assisted imaging and the Image-J analysis program. Data were analyzed statistically by ANOVA followed by Fisher PLSD individual group comparisons, reciprocal transforming data as need to normalize distributions. 
Table 5. Effect of LY379268 on Strial Projection Neurons in GPe of R6/2 Mice

\begin{tabular}{lllll}
\hline $\begin{array}{l}\text { Mouse } \\
\text { Groups }\end{array}$ & $\begin{array}{l}\text { \# of } \\
\text { Mice }\end{array}$ & $\begin{array}{l}\text { Mean } \\
\text { Repeat } \\
\text { Length }\end{array}$ & $\begin{array}{l}\text { \% of GPe Covered by } \\
\text { ENK+ Fibers from } \\
\text { Indirect Pathway } \\
\text { Neurons }\end{array}$ & $\begin{array}{l}\text { Intensity of ENK+ Fibers } \\
\text { in GPe Arising from } \\
\text { Indirect Pathway Neurons }\end{array}$ \\
\hline $\begin{array}{l}\text { WT }- \\
\text { Vehicle }\end{array}$ & 8 & N/A & $100 \%$ & $100 \%$ \\
$\begin{array}{l}\text { WT }- \\
\text { LY379268 }\end{array}$ & 8 & N/A & $97.1 \%$ & $109.0 \%$ \\
$\begin{array}{l}\text { R6/2- } \\
\text { Vehicle }\end{array}$ & 9 & 118.3 & $92.5 \% *$ & $106.5 \%$ \\
$\begin{array}{l}\text { R6/2- } \\
\text { LY379268 }\end{array}$ & 8 & 119.1 & $93.4 \%$ & $108.6 \%$ \\
\hline
\end{tabular}

Note: *significantly different from WT-Vehicle 


\section{ENK In Situ Hybridization Analysis}

No significant differences were seen between WT-LY compared to WT-vehicle mice in total striatal ENK signal. Thus, LY379268 did not affect ENK + striatal neurons in a way that affected ENK message in WT mice. By contrast, in R6/2-V mice overall striatal signal was greatly and significantly reduced (32.4\% of WT-V). The overall striatal signal was also similar in the R6/2-LY mice, and was also significantly less than in WT-V (32.5\% of WT-V). The ENK signal per perikaryon also did not differ between wildtype groups, but was reduced by about $50 \%$ in both R6/2 groups. Thus, as in the case of our ENK immunolabeling of the indirect pathway striatal projection to GPe, there was no benefit of LY379268 treatment for the ENK+ striatal neuronal population. These results are seen in Table 6 .

\section{SP In Situ Hybridization Analysis}

As in the case of ENK message, no significant differences were seen between WT-LY compared to WT-vehicle mice in total striatal SP signal. Thus, LY379268 did not affect SP+ striatal neurons in a way that affected SP message in WT mice (Table 7). Total SP+ signal in the striatum of R6/2-V was $84.4 \%$ of WT-V, while in R6/2 mice receiving LY379268 total striatal SP+ signal was elevated to $14.3 \%$ above WT-V. Similarly, SP signal per perikaryon was reduced to $81.5 \%$ of WT-V in the R6/2-V mice, a significant reduction, but was not significantly different form either WT group in the R6/2-LY mice. Thus, by both immunolabeling and ISH, the data indicate LY379268 to benefit $\mathrm{SP}+$ striatal neurons in $\mathrm{R} 6 / 2$ mice.

\section{Behavioral Analysis}

\section{Survival}

Figure 2 shows cumulative survival for the thirty-two $20 \mathrm{mg} / \mathrm{kg}$ LY-treated (LY) and 30 control-treated R6/2 mice. The benefit of daily $20 \mathrm{mg} / \mathrm{kg}$ LY379268 is evident. Lifespan was studied in $32 \mathrm{R} 6 / 2$ mice treated with $20 \mathrm{mg} / \mathrm{kg}$ of LY379268 daily, $17 \mathrm{R} 6 / 2$ mice with vehicle, and $13 \mathrm{R} 6 / 2$ mice with $10 \mathrm{mg} / \mathrm{kg} \mathrm{LY379268.} \mathrm{There} \mathrm{was} \mathrm{no} \mathrm{significant}$ difference in survival benefit between the R6/2 mice treated with $10 \mathrm{mg} / \mathrm{kg}$ of LY and the vehicle treated group, thus these two groups were combined and compared with the R6/2 mice treated with $20 \mathrm{mg} / \mathrm{kg}$ of LY379268. This dose was selected as the maximum tolerated dose (MTD) in tests on R6/2 mice carried out prior to the benefit assessments, using an MTD protocol recommended by the funding agency for this research, the Cure HD Initiative Foundation. The average CAG repeat length was 124.0 for the LY-treated R6/2 mice, and 123.6 for the control-treated R6/2 mice. There was no significant difference between CAG repeat lengths between males and females. The mean survival was significantly longer in the $20 \mathrm{mg} / \mathrm{kg} \mathrm{LY}$-treated than the control-treated R6/2 mice 
Table 6. LY379268 on ENK in Striatal Projection Neurons as a \% of WT-Vehicle

\begin{tabular}{lllll}
\hline $\begin{array}{l}\text { Mouse } \\
\text { Groups }\end{array}$ & $\begin{array}{l}\text { \# of } \\
\text { Mice }\end{array}$ & $\begin{array}{l}\text { Mean Repeat } \\
\text { Length }\end{array}$ & $\begin{array}{l}\text { Intensity of ENK+ ISH } \\
\text { Signal per Perikaryon }\end{array}$ & $\begin{array}{l}\text { Total ENK+ Signal } \\
\text { in Striatum }\end{array}$ \\
\hline WT - Vehicle & 10 & N/A & $100 \%$ & $100 \%$ \\
WT - & 9 & N/A & $103.8 \%$ & $107.9 \%$ \\
$\begin{array}{l}\text { LY379268 } \\
\text { R6/2- }\end{array}$ & 9 & 123.8 & $49.6 \% * \wedge$ & $32.4 \% * \wedge$ \\
$\begin{array}{l}\text { Vehicle } \\
\text { R6/2- }\end{array}$ & 11 & 124.7 & $50.3 \% * \wedge$ & $32.5 \% * \wedge$ \\
LY379268 & & & & \\
\hline
\end{tabular}

Note: *significantly different from WT-Vehicle; ^significantly different from WTLY379268

Table 7. LY379268 on SP in Striatal Projection Neurons as a \% of WT-Vehicle

\begin{tabular}{lllll}
\hline Mouse Groups \# of & $\begin{array}{l}\text { Mean Repeat } \\
\text { Mice }\end{array}$ & $\begin{array}{l}\text { Intensity of SP+ ISH Signal } \\
\text { per Perikaryon }\end{array}$ & $\begin{array}{l}\text { Total SP+ Signal in } \\
\text { Striatum }\end{array}$ \\
\hline WT - Vehicle & 10 & N/A & $100 \%$ & $100 \%$ \\
WT - & 10 & N/A & $96.7 \%$ & $90.3 \%$ \\
LY379268 & & & $81.5 \% * \wedge$ & $84.4 \%$ \\
$\begin{array}{l}\text { R6/2 }- \\
\text { Vehicle }\end{array}$ & 8 & 123.9 & $90.2 \%$ & $114.3 \% \#$ \\
R6/2- & 10 & 124.7 & & \\
LY379268 & & & & \\
\hline
\end{tabular}

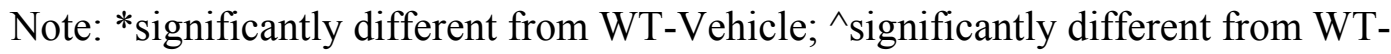
LY379268; \#significantly different from R6/2-Vehicle 


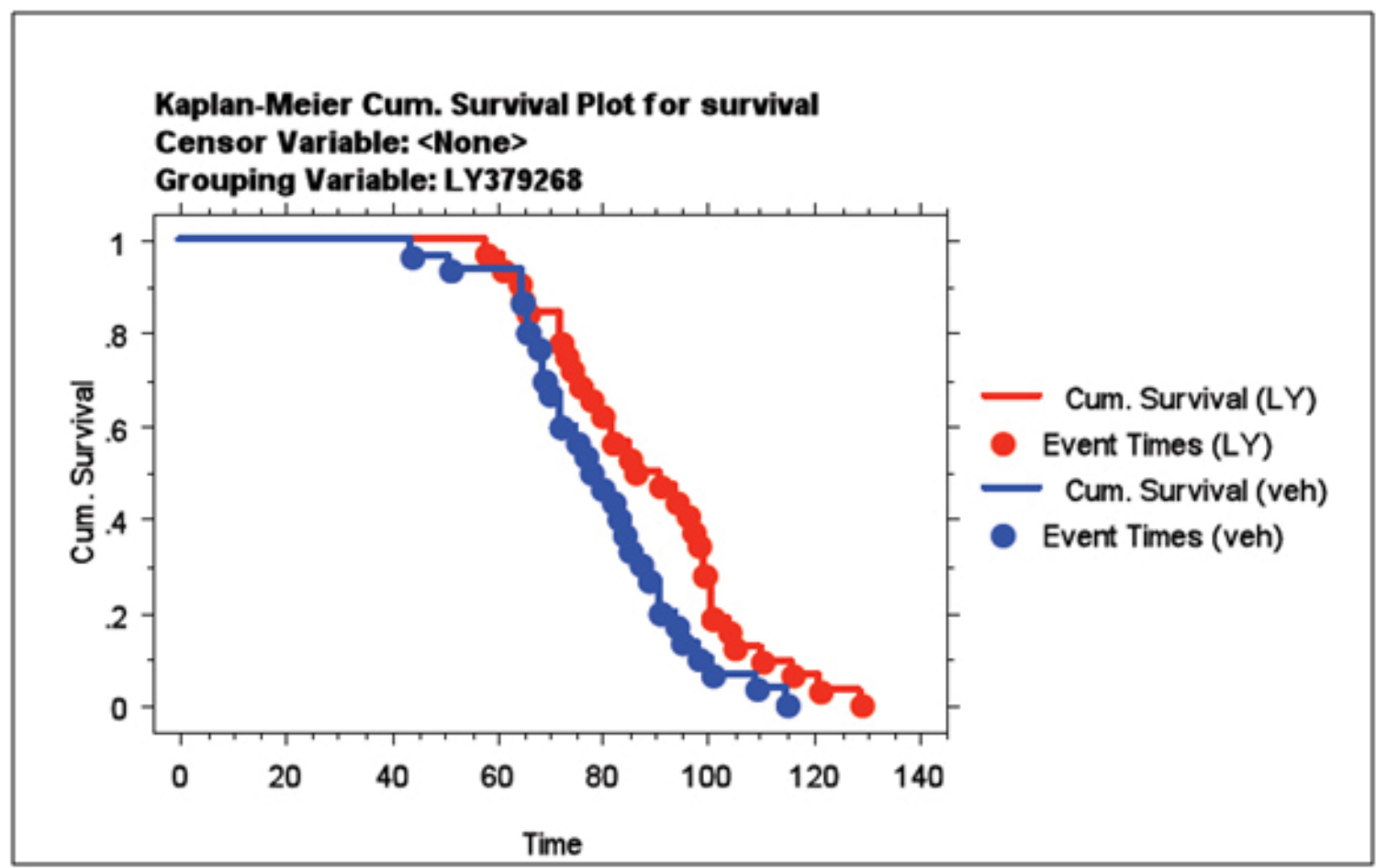

Figure 2. Survival 
(88.5 days in drug-treated vs. 79.7 days in control-treated), by Mantel-Cox logrank test (p $=0.0276)$. There was a 9-day benefit for males and female mice treated with $20 \mathrm{mg} / \mathrm{kg}$ of LY. Measured lifespan was 4 days less on average with males in both the control group and those receiving $20 \mathrm{mg} / \mathrm{kg}$ of $\mathrm{LY}$.

\section{Body Weight}

Figure 3 shows that mean body weight was persistently slightly lower in the 19 LY-treated WT mice (red) than in the 19 vehicle-treated WT mice (blue). This becomes apparent after 8 weeks. The 32 R6/2 mice treated with LY379268 (green) had a lower body weight than the 30 control R6/2 mice beginning at 13 weeks of life. Statistical analysis, however, did not show a significant effect of drug on body weight throughout the testing period, nor for the R6/2 mice at $14-16$ weeks $(p=.08)$. Thus, any effect of drug on body weight is slight and variable. ANOVA analysis did not reveal a significant effect of the drug-genotype interaction, indicating that any effects on body weight of $20 \mathrm{mg} / \mathrm{kg}$ LY were similar irrespective of gender. There were however, significant effects of gender (males heavier than females in WT, females heavier than males in R6/2) and genotype (WT heavier than R6/2) on body weight.

\section{Rotarod Performance}

Figure 4 shows that LY379268 did not improve rotarod performance in 32 R6/2 mouse treated with a daily $20 \mathrm{mg} / \mathrm{kg}$ dose. There was no discernable benefit of rotarod performance between LY and Vehicle treated R6/2 mice as seen with the blue and red lines in the figure. The R6/2 mice have an inferior performance at all time points when compared to the WT mice. The drug did not hinder rotarod performance in WT mice.

\section{Open Field Measurements}

\section{Total Distance Traveled in Centimeters during 30 Minutes}

As seen in Figure 5, vehicle-treated R6/2 mice locomote much less than WT mice during the 30-min session (i.e. are less active and cover less total distance), and the LY drug yielded better performance in R6/2 mice on this endpoint than observed in the vehicle-treated R6/2 mice at all ages. Of particular note, the LY drug normalized total locomotor activity until about 12 weeks of age. The benefit was comparable in males and females. The drug did not have an obvious deleterious effect on the WT mice in their total distance traveled. These observations were confirmed by ANOVA, which detected significant effects of genotype, drug and the drug-genotype interaction on distance traveled. 


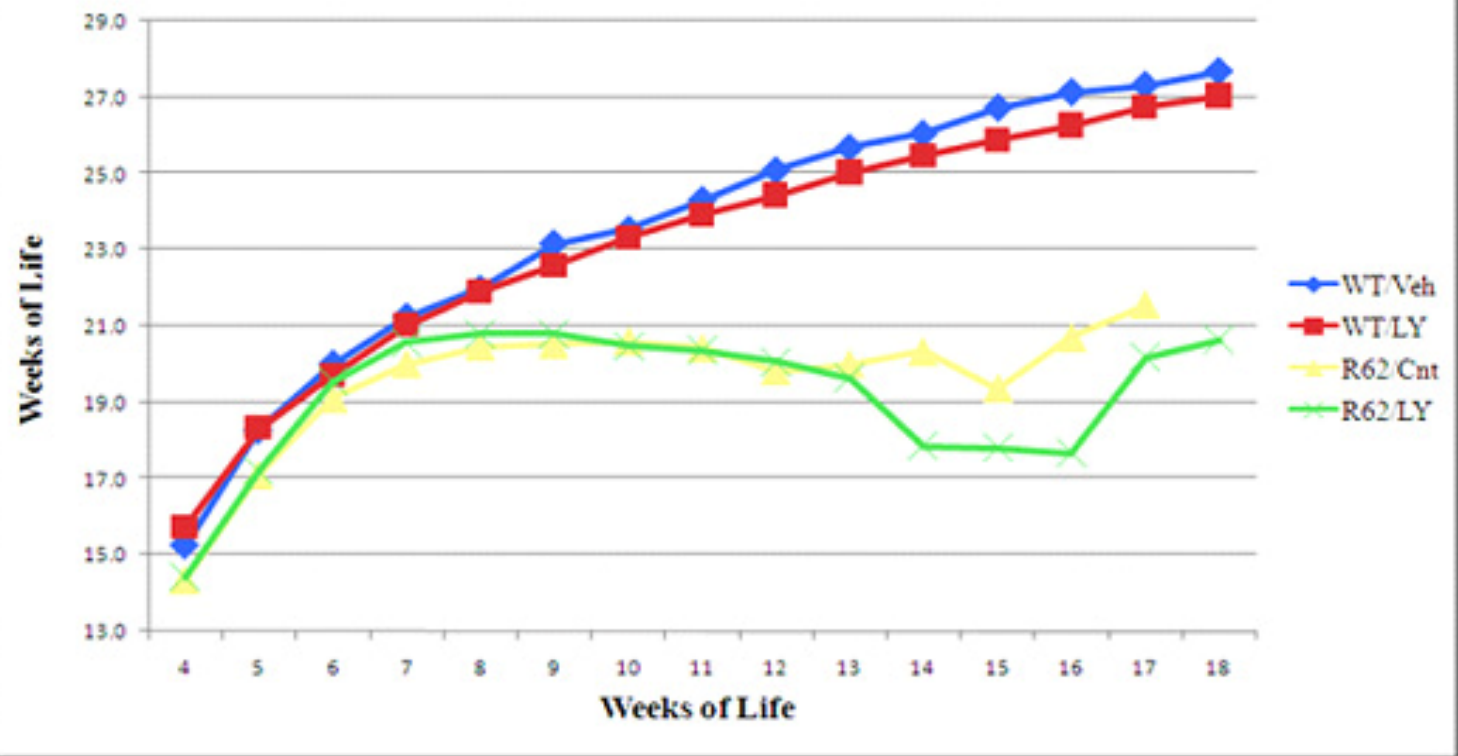

Figure 3. Effect of LY379268 on Body Weight 


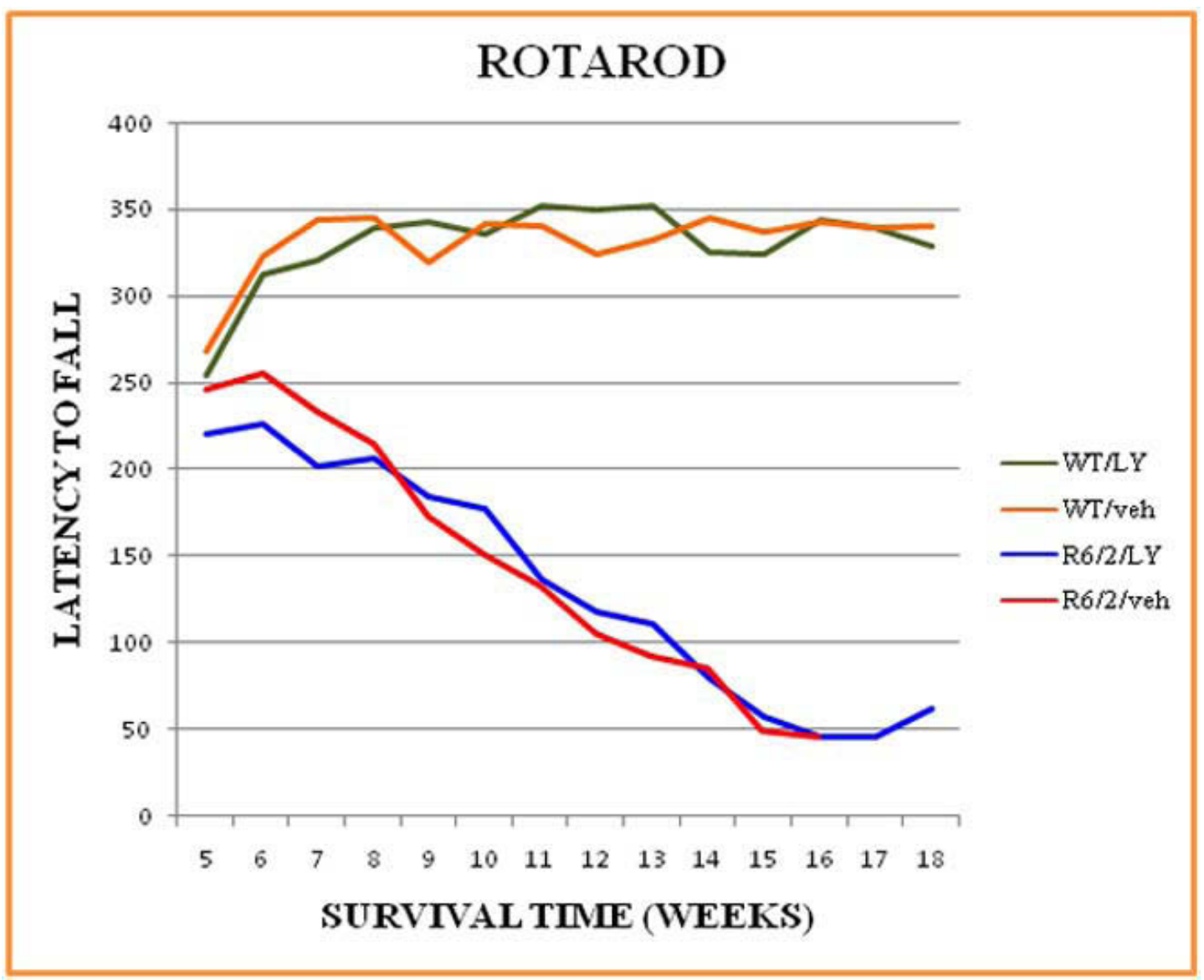

Figure 4. Rotarod Performance 


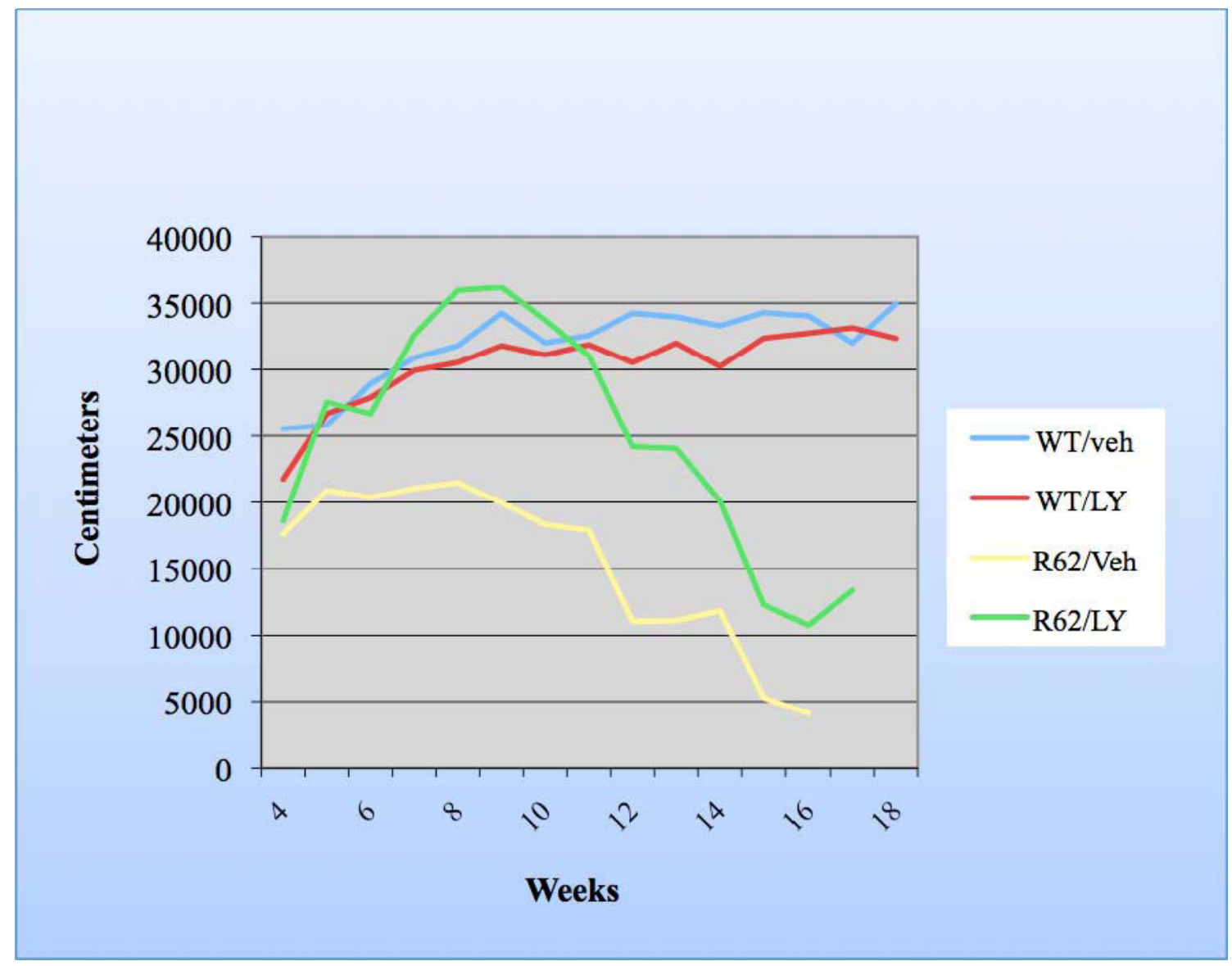

Figure 5. Total Distance Traveled in Centimeters during 30 Minute Session 


\section{Median Progression Segment Length}

Figure 6 shows an underpinning of the decreased distance traveled in vehicletreated R6/2 mice, in that it shows that vehicle-treated R6/2 mice traversed shorter distances during their bursts of locomotion (called progression segments in the Drai and Golani lexicon) than did normal mice. Treatment of LY397268 in R6/2 mice showed an improvement in this parameter and progression segment length increased over those measured in WT mice between weeks 8 and 12 of life. These observations were confirmed by ANOVA, which detected significant effects of genotype, drug and the drug-genotype interaction on progression segment length.

\section{Time Proportion Spent Lingering}

Figure 7 shows that vehicle-treated R6/2 mice spent a greater proportion of the time between progression segments in pauses called lingering episodes than did WT mice. These pauses contributed to the overall decrease in activity in the vehicle-treated $\mathrm{R} 6 / 2$ mice. Note that the total proportion of time spent lingering is greater in vehicletreated R6/2 than WT mice, and increases as the mice age. ANOVA confirmed a benefit of LY379268, with less lingering occurring, since significant effects of genotype, drug and genotype-drug interaction occur for the 9-17 week period (when the defect in vehicle-treated $\mathrm{R} 6 / 2$ mice becomes prominent).

\section{Progression Segment Maximum Speed}

Figure 8 shows that maximum locomotor speed during progression segments was much less in vehicle-treated R6/2 mice than in WT mice, and progressively worsened as the R6/2 mice approached the end of their lifespan. The LY drug strikingly improved R6/2 mice on this motor parameter. ANOVA confirmed a benefit of LY379268 in R6/2 mice on maximum locomotor speed, since significant effects of genotype, drug and genotype-drug interaction were observed.

\section{Median Curvature of Progression Segments}

Figure 9 shows that vehicle-treated R6/2 mice had increasing difficulty walking in a straight line (i.e. the curvature of their progression segments was increased), and also shows that the LY compound strikingly normalized R6/2 mice on this parameter for much of their lifespan. Beyond 15 weeks, path curvature in vehicle-treated R6/2 was diminished, as the shorter progression segments in the few surviving vehicle-treated mice may have made it easier for the mice to walk a straight line. ANOVA confirmed that for the period over which vehicle-treated R6/2 mice showed a progressive impairment, the drug was beneficial in the R6/2 LY-treated mice, since significant effects of drug, and drug-genotype interaction were seen for the $9-15$ week period. 


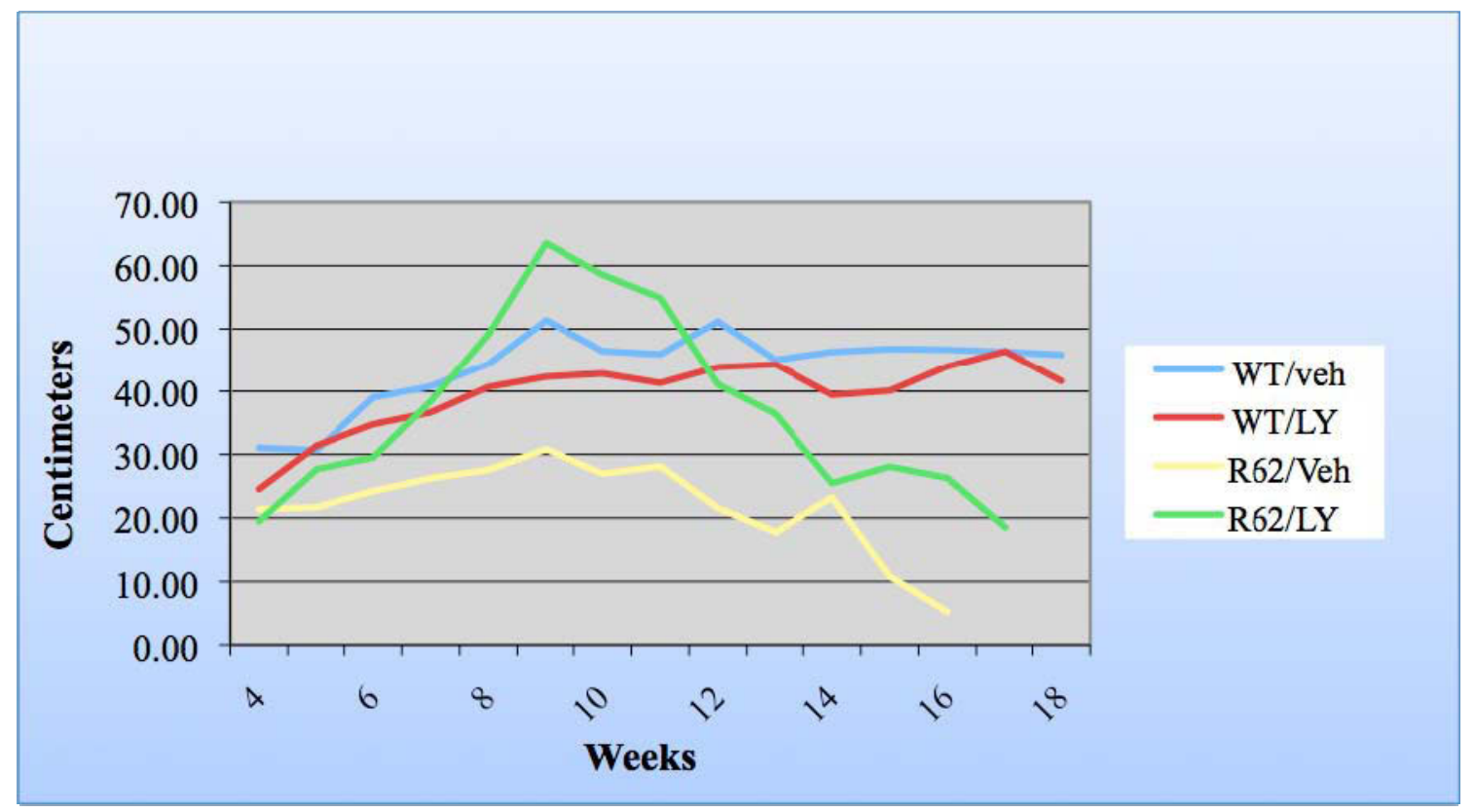

Figure 6. Median Progression Length 


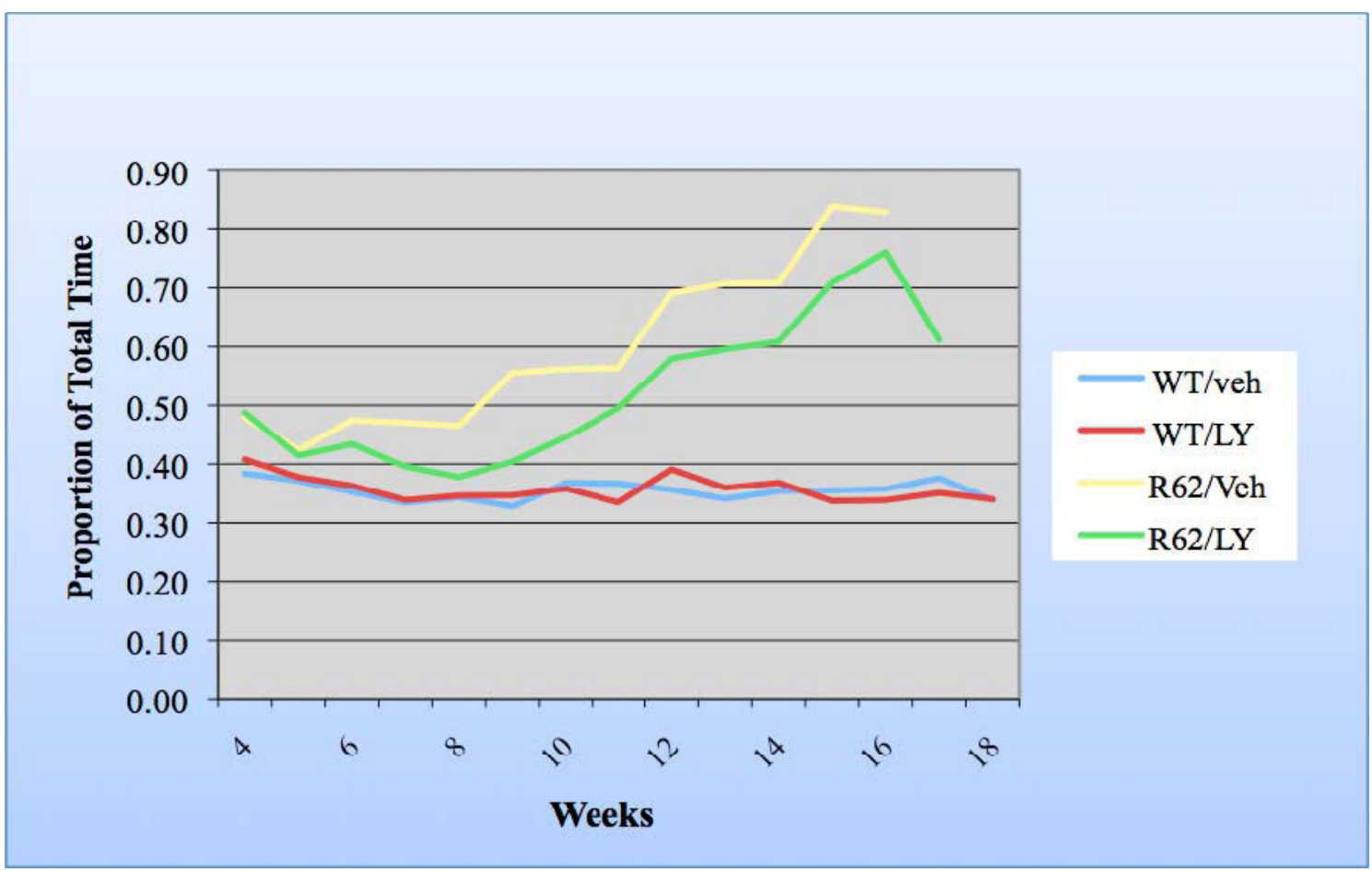

Figure 7. Time Proportion Spent Lingering 


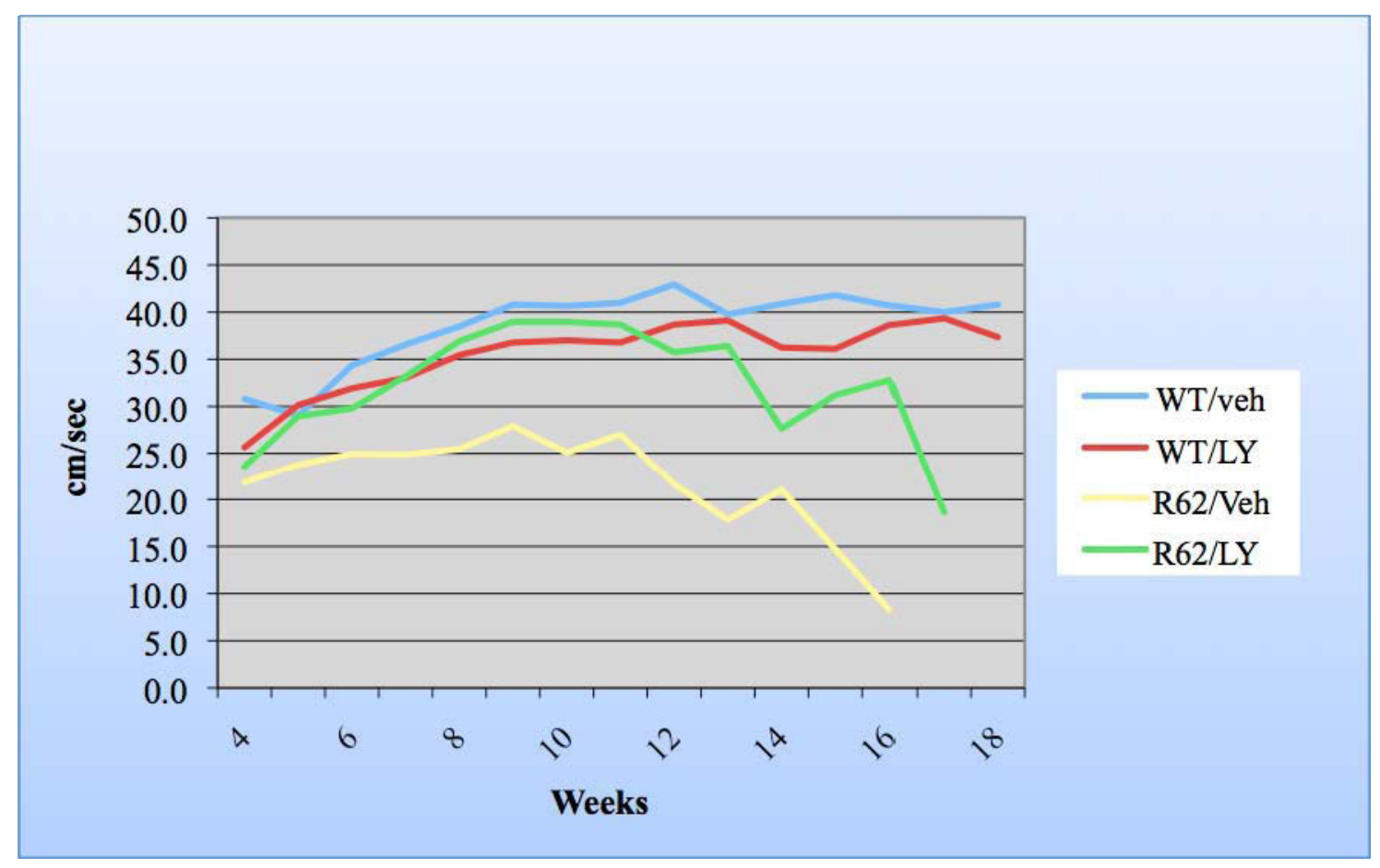

Figure 8. Maximum Progression Speed 


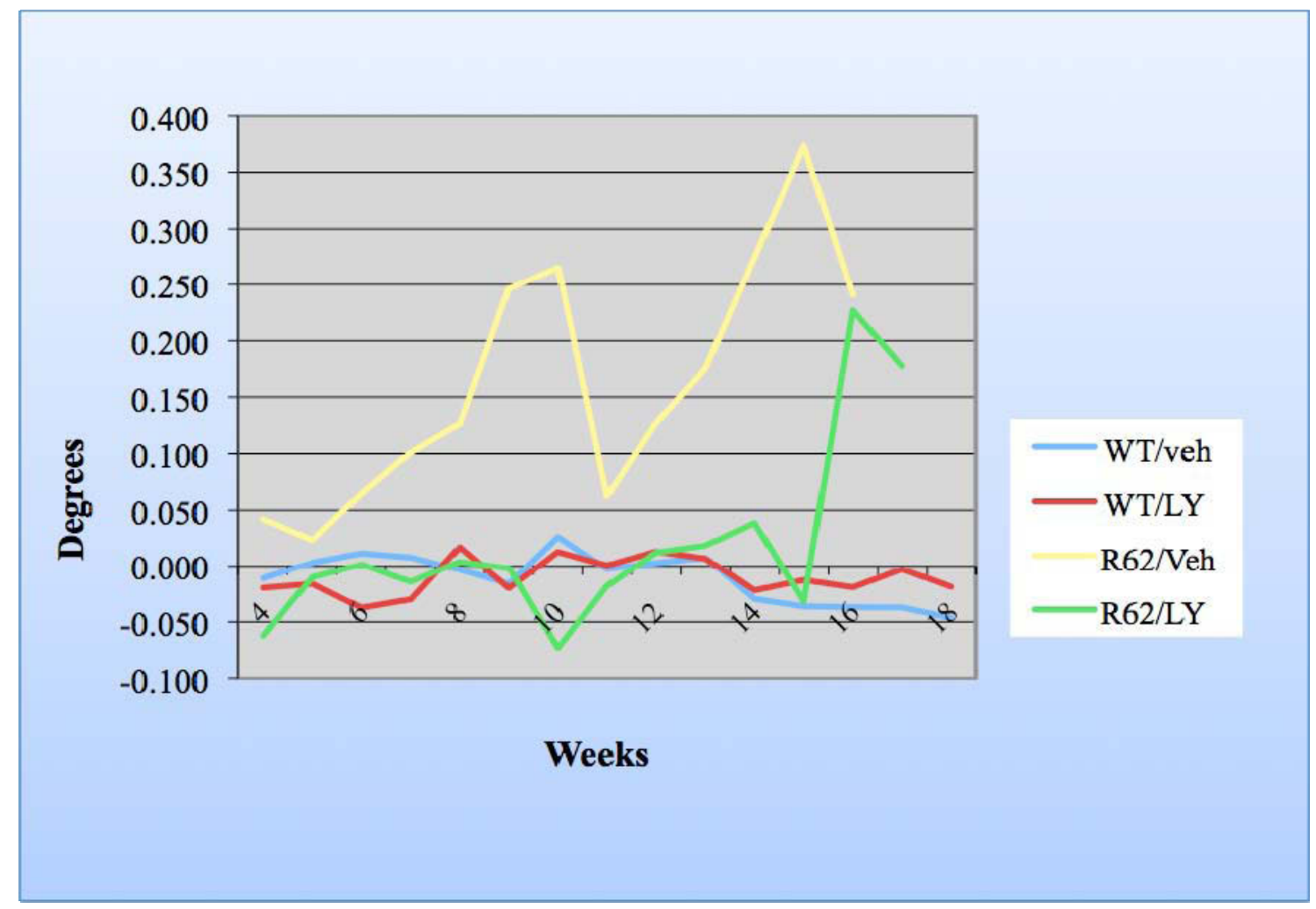

Figure 9. Median Curvature of Progression 


\section{CHAPTER 5. DISCUSSION}

Our results show several benefits of daily injections of an MTD of LY379268 in R6/2 mice. These beneficial effects of this mGluR2/3 agonist include normalized motor parameters at 4-12 weeks in the open field task, including normalized speed, acceleration, endurance and overall activity. Morphological improvement was seen as well in terms of rescue of cortical and striatal neurons, and normalization of the $\mathrm{SP}+$ striatal projection neurons was apparent at 10 weeks. The results for SP neurons are particularly interesting because SP neurons are part of the direct pathway which is responsible for voluntary movement (Albin et al 1992; Reiner et al 1988). Impairments to this pathway result in hypoactivity (Alexander \& Crutcher 1990; DeLong 1990; Reiner et al 1988), and it is possible that a defect in this pathway contributed to the decline of open field activity in $\mathrm{R} 6 / 2$ mice that was observed. It is particularly interesting to note, thus, that the akinesia of the R6/2 mice (e.g. reduced open field activity) was accompanied by the normalization of the SP pathway. These findings will be discussed in more detail below, as well as the means by which the LY compound could have produced its improvement.

\section{Neuropathology and Behavior Correlations}

The phenotype and neuropathology of R6/2 mice replicate several features of the disease observed in humans, including altered levels of neurotransmitters and neuropeptides in the basal ganglia (Cha 2000). As in HD, the striatal projection neurons of R6/2 mice are not uniformly affected over the course of the disease (Cha et al 1998; Luthi-Carter et al 2000; Menalled et al 2000). Immunohistochemistry has shown in human HD that ENK and SP levels differ in their target areas based on the stage of the disease (Reiner et al 1988). ENK fibers projecting to the GPe are lost sooner than SP fibers projecting to GPi (Deng et al 2004; Reiner et al 1988). Analysis of the GPe in R6/2 mice at 12 weeks of age also showed a decrease in ENK labeled fibers in GPe, but no significant change was reported in the measured SP labeled fibers (Sun et al 2002). Our study of R6/2 mice at 10 weeks of age showed a slightly elevated SPimmunoreactive fiber intensity for striatal projection fibers to GPi and a substantial elevation for SN. This increase for SP-immunolabeled fibers projecting to SN has been depicted in other studies, but has not been commented upon (Menalled et al 2000; Sun et al 2002). Our in situ hybridization data for 10-week R6/2 mice showed a significantly decreased overall message for ENK (30\% of WT) and slight decrease in SP ( $85 \%$ of WT) message in striatum. This matches previous in situ hybridization studies on 12-week $\mathrm{R} 6 / 2$ mice that showed enkephalin mRNA is reduced in striatal neurons to a greater extent than substance P mRNA (Menalled et al 2000; Sun et al 2002). Similarly, a microarray study of R6/2 mice at 12 weeks of age showed a decreased expression of enkephalin mRNA from striatum, but no major changes were seen in Substance P mRNA (Luthi-Carter et al 2000). Such results show that the increase in SP in the GPi and SN do not stem from an increase in SP production. An interpretation is that the increase in SP in striato-GPi and striato-SN reflects a failure of peptide release, since less mRNA is being made, yet more peptide is present in the terminals. An argument could be made that the 
SP retention in $\mathrm{R} 6 / 2$ striatal projection neuron terminals thus reflects neuronal dysfunction. Previous immunohistochemical studies have shown that ablation of corticostriatal neurons results in increased SP levels of SN in rats (Bouras et al 1991; Somers \& Beckstead 1990). These authors attribute this effect to a loss of cortical activation of striatal neurons, with a subsequent diminution of SP release (Bouras et al 1991). Alterations in the firing activity of neurons have been observed in the striatum of awake- behaving R6/2 mice that may account for the failure of peptide release in striatal target areas. In particular, Rebec and coworkers have noted that MSNs of R6/2 mice are slightly more active than in WT mice, but they fail to show the type of burst activity that ensues from cortical activation (Miller et al 2008; Rebec et al 2002). Burst activity, which represents spike clusters of varying rates and duration, provide information coding by assemblies of neurons (Sakurai 1999; Salinas \& Sejnowski 2001). Burst firing ensures reliable transmission between neurons and induces synaptic plasticity in the striatum (Charpier \& Deniau 1997; Lisman 1997). This dysregulation of firing could alter downstream neurotransmitter release of either ENK or SP projection neurons. In the present study, daily injections of LY379268 rendered SP levels in SN down to $130 \%$ of WT as opposed to the level of $160 \%$ seen with vehicle-treated R6/2. Likewise, SP levels in LY-treated R6/2 mice were down in GPi to 122\% compared to the vehicle-treated R6/2 mice measured at $132 \%$. Thus, the LY379268 compound relatively normalized SP levels in GPi and SN.

Our results show that ENK message is greatly reduced but an apparent retention of the peptide results in normal ENK levels in striato-GPe terminals, thus disguising the fact that less ENK is being made. The retention is more obvious with the SP projection neurons because the message is not as greatly diminished, so the peptide retention yields peptide levels above normal. Although SP peptide levels are relatively normalized with LY379268 in GPi and SN, the same effect is not seen with ENK levels in GPe. This is consistent with our in situ hybridization data showing the LY compound normalized SP message but did not alter ENK message in R6/2 mice. This implies that the LY379268 benefit is specific to SP neurons. The Direct-Indirect pathway model of basal ganglia function (DeLong 1990) proposes that voluntary movement would be normalized with restored function of SP neurons, which our behavioral data reflects. It would be of interest to know if burst firing is restored in R6/2 mice with administration of LY379268. Research has also shown that a modulator of striatal activity is extracellular levels of ascorbate (Rebec et al 2005; Rice 2000). Ascorbate interacts with the glutamate transporter in a heteroexchange mechanism, whereby glutamate is taken up and ascorbate is transported out of astrocytes (Cortright \& Rebec 2006; Grunewald \& Fillenz 1984). It would be interesting to know if striatal levels of ascorbate increase with administration of the LY379268.

Although R6/2 mice show gross brain and striatal atrophy (Mangiarini et al 1996), neuronal loss has only been reported in one study. Stack et al, (2005) showed a $25 \%$ decrease in total number of striatal neurons in 12-week old R6 / 2 mice. Our current results show a $20 \%$ loss of striatal neurons in 10 -week old R6/2 mice, which was normalized with administration of LY379268. Although it has been suggested that neuron loss does not occur in R6/2 mice (Li \& Li 2004b; Reddy et al 1999), differences 
in methodology might account for the difference in outcomes. Stereology as used in the current study was also used by Stack et al (2005), and is a more sensitive approach for detecting neuron loss. A distinction could not be made with stereology, however, as to which population of striatal projection neurons was more decreased, but it would be interesting to know if the benefit seen in neuron rescue by the LY compound affected primarily the SP pathway.

The R6/2 mouse typically shows enlarged lateral ventricles with coinciding striatal atrophy at 13 weeks (Mangiarini et al 1996). Volumetric data on striatum, lateral ventricle, and cortex was expressed scaled allometrically to body weight, because of the effect of genotype on animal size. By this standard, telencephalic and cortical volume did not differ among the groups, but ventricular size was doubled in the R6/2 mice. LY379268 treatment did not affect ventricular volume in the R6/2 mice. The ventricular volume increase is suggestive of cortical, septal and/or striatal atrophy, but the only significant effect for any of these seen in the R6/2 mice was for striatal volume, which was about $10 \%$ smaller in the R6/2-LY mice. Overall, these data indicate minimal cortical or striatal shrinkage in the R6/2 mice at 10 weeks, and no evident benefit of LY379268 in the R6/2 mice.

\section{Pathogenic Mechanisms}

There are a variety of means by which LY379268 could have produced its improvement. The compound may have opposed excitotoxic striatal injury (D'Onofrio et al 2001; Kingston et al 1999). There are several possible ways it could have done this. Since there are mGluR2/3 receptors on cortical terminals, the drug may have acted by reducing presynaptic release of glutamate (Battaglia et al 1997; Cozzi et al 1997). This alone would have an effect that would oppose excitotoxicity. In principle, reducing presynaptic glutamate release should reduce excitotoxicity, and reduce striatal pathology in HD. One prior study prevented corticostriatal glutamate release in R6/2 mice by ablating cortical neurons and eliminated loss of striatal neurons and striatal shrinkage (Stack et al 2007). LY379268 may have also acted directly on striatal neurons, because mGluR3 is found on some subset of striatal neurons (Testa et al 1994), although it has not been established which subset. A third possibility for a mechanism of action is that LY379268 could have increased trophic substance production from striatal astrocytes. In a prior study, TGF- $\beta$ production was enhanced in striatal glial cells with administration of LY379268 (D'Onofrio et al 2001). Another possible mechanism of action is that cortical BDNF was upregulated with the LY compound, as shown to occur in mice (Di Liberto et al 2010), which would be beneficial for striatal neurons (Canals et al 2004; Zuccato \& Cattaneo 2007). Each of these possible mechanisms will be addressed in further detail below.

The notion that excess cortical glutamate release mediates striatal injury presupposes that striatal injury is caused by excitotoxicity, and many lines of evidence suggest this is so. Since NMDA receptor agonists injected into striatum produce a pattern of striatal injury that closely mimics HD pathology (Figueredo-Cardenas et al 
1994; Shear et al 1998), it has widely been thought that excitotoxicity is involved in HD. Several lines of research suggest HD pathology stemming from excitotoxic injury to the striatum is specifically mediated through extrasynaptic NMDA receptors on the striatal projection neurons. Notably, NMDA current is enhanced in HD transgenic mice (Andre et al 2006; Cepeda et al 2001; Fan \& Raymond 2007; Li et al 2004), and the enhanced NMDA response stems from increased expression of the extrasynaptic receptors NMDA of striatal projection neurons (Fan et al 2007). Activation of these receptors requires glutamate spill from the synaptic sites to the extrasynaptic sites (Milnerwood et al 2010). Such activation can enhance mhtt cleavage in toxic fragments, and thus make neurons more vulnerable to death via decreased CREB-PGC-1 $\alpha$ activity (Cui et al 2006; Milnerwood et al 2010; Papadia et al 2008; Subramaniam et al 2009). Cleaved mhtt is soluble and binds to CREB binding protein, thus interfering with gene transcription (Nucifora et al 2001). In mhtt-transfected neurons, CREB function was restored by selectively blocking the extrasynaptic NMDA receptors with low dose memantine (Okamoto et al 2009). This same study also showed improved rotarod performance in YAC128 mice with this low dose (Okamoto et al 2009). There seems to be an excitatory balance needed for neuroprotection since high dose memantine blocked beneficial synaptic NMDA receptor activity, thus increasing soluble mhtt and worsening the phenotype in this study (Okamoto et al 2009). By contrast, low-dose memantine allowed synaptic receptor activation that was beneficial for cell survival, with consequences such as reducing soluble mhtt, increasing mhtt aggregate size and stimulating the CREB pathway (Okamoto et al 2009). There is also altered glutamate release from corticostriatal synapses in HD mice prior to motor pathology (Cepeda et al 2003), and electrophysiological studies have shown an increase of glutamate release from corticostriatal terminals at an early age (Cepeda et al 2007; Joshi et al 2009). Glutamate is normally taken up via excitatory amino acid transporters, in particular GLT1, (Shigeri et al 2004), and there is decreased expression of this transporter in astrocytes of HD mice and HD humans (Behrens et al 2002; Hassel et al 2008; Lievens et al 2000; Shin et al 2005). If LY397268 acts pre-synaptically for its benefit, then excess glutamate release and spillover would be attenuated, and less would reach the extrasynaptic NMDA receptors. If the mechanism of action of the LY compound is post-synaptic (as discussed in the next paragraph), then the effect would dampen the activity of the striatal neurons and produce its benefit in that way. Neither of these mechanisms gives a clear reason why our results showed a greater benefit on SP neurons rather than ENK neurons. It was previously shown that upper layer V cortical neurons project specifically to striatal SP neurons (Lei et al 2004), but it is not clear if mGluR2/3 receptors are more abundant on that particular cortical neuron type.

It is possible that the benefit of LY379268 arises by a direct action on striatal projection neurons. An overview of the distribution and mechanism of action of the mGluR $2 / 3$ receptors in the striatum offers insight into the basis of potential benefit seen in our results. Within the striatum, mGluR2 receptors are only found in cholinergic neurons and not projection neurons (Testa et al 1994). The mGluR3 receptors in the striatum are on astrocytes as well as on neurons (Testa et al 1994). It is of interest to note that examination of images in the Allen Brain Atlas indicates approximately $50 \%$ of the striatal neurons contain mGluR3, and it is known that approximately $50 \%$ of the striatal 
projection neurons are SP neurons (Gerfen et al 1990; Reiner et al 1988). If the SP neurons are the same neurons that contain mGluR3, then the benefit of LY379268 could be achieved by direct striatal action. Activation of mGluR3 is coupled to inhibition of the cyclic AMP pathway (Nakanishi 1992; Schoepp et al 1999). This results in decreased membrane excitability stemming from reduced Ca2+ current via N, L-type Ca2+ channels and increased K+ current via IRKC channels (Davies et al 1995; King \& Liu 1996; McCool et al 1996). If the benefit of LY379268 was achieved in this manner, it should be possible to see the same effects if the R6/2 mice are treated with a dopamine D1 receptor antagonist, since this would also yield reduced activation of the cAMP pathway (Monsma et al 1990). Further studies are needed to firmly establish the location of mGluR3 receptors on striatal projection neurons.

As mentioned above, the benefit of the LY compound could have come about by an increased production of TGF- $\beta$ in the striatum. It has been shown that activation of mGluR3 receptors mediates striatal neuroprotection via glial-neuronal interaction (Bruno et al 1997). This neuroprotection comes about from TGF- $\beta$ released from astrocytes, and is effective in preventing NMDA toxicity in in vitro and in vivo models (Bruno et al 1997; Bruno et al 1998). Systemic administration of LY379268 in mGluR3 knock-out mice failed to give neuroprotection to striatal neurons against NMDA toxicity (Corti et al 2007). This same study showed that the neuroprotection was abolished in cultured neurons with astrocytes lacking mGlur3 receptors (Corti et al 2007). These studies suggest that activation of mGluR3 receptors on the striatal astrocytes offer neuroprotection. The neuroprotection from TGF- $\beta$ could also arise through a different mechanism other than preventing excitotoxicity, including preventing neuronal apoptosis (Copani et al 1995; Ren et al 1997). Activation of TGF- $\beta$ receptors leads to phosphorylation of Smad2, a transcription factor, which activates gene expression (Massaous \& Hata 1997) involved with inhibiting cyclin-dependent kinases involved with cell cycle check points (Datto et al 1995). This mechanism is relevant because inducing an abortive mitotic cycle has been related to the occurrence of neuronal degeneration (Freeman et al 1994; Herrup \& Busser 1995). A study showed that cyclin D1 and E2F-1 are over-expressed in brains of HD patients (Pelegri et al 2008). There is evidence showing these two proteins are involved with abortive cell cycle re-entry in neurons (Camins et al 2007; Krantic et al 2005), with subsequent neurodegeneration due to oxidative stress and apoptosis (Pelegri et al 2008; Woods et al 2007; Zhu et al 2007).

In addition to TGF- $\beta$, BDNF increase by LY379268 administration could play a role in neuroprotection. BDNF is known to promote development, differentiation, plasticity and survival of neurons in several regions of the brain including striatum (Lessmann et al 2003; Poo 2001; Zuccato \& Cattaneo 2007). It is known that mhtt in HD reduces the transcription of the BDNF gene in the cortex of HD mice and thus decreases protein production (Zuccato et al 2001). These authors showed that cortical BDNF mRNA decreased with progression of behavioral symptoms in R6/2 mice (Zuccato et al 2005). A study of a cortex specific knock-out model of the BDNF gene showed a progression of the disease that mimicked the pathology of human HD in terms of striatal degeneration (Strand et al 2007). Conversely, behavioral performance was improved and disease progression slowed in an HD mouse crossed with mice overexpressing BDNF 
(Gharami et al 2008). These lines of evidence suggest that a deficit in BDNF contributes to the pathogenesis of striatal injury in HD, thus making it a candidate as a therapeutic agent. Another study showed daily intrastriatal administration of BDNF in R6/1 HD mice increases the number of striatal neurons expressing enkephalin and resulted in improvement in behavioral phenotypes (Canals et al 2004). Conversely, in R6/1 on a hemizygous BDNF knock-out background, striatal ENK expression but not SP expression is reduced (Canals et al 2004). This suggests that endogenous BDNF might delay the progression of HD in humans. A recent study showed mice acutely treated with LY379268 showed an upregulation of BDNF in cortex and hippocampus (Di Liberto et al 2010). The various lines of studies reviewed above give credence to the idea that the benefit from the LY compound stems from a possible increase in cortical BDNF in the mice. Despite this evidence that BDNF must be involved with striatal neuron health, Stack et al (2007) showed that decortication in R6/2 mice improves striatal neuropathological phenotypes and restores striatal neuron loss to WT levels. This argues against the idea that striatal neuron loss in R6/2 mice stems from BDNF deprivation because decortication would only exacerbate the BDNF deficit. The study of Canals (2004) showing BDNF benefit for ENK but not SP neurons provides further evidence that BDNF was unlikely to have been the basis for our striatal benefit observed with LY379268 since a large benefit for striatal neurons containing ENK was not seen by us. The benefit of LY379268 in the present study was seen for striatal neurons containing SP. It is likely thus that the striatal benefit of LY379268 does not involve a BDNF mechanism, since our results show little benefit with ENK neurons. It is possible that the cortical BDNF upregulation caused by LY379268 benefits cortex, and explained the rescue of cortical neurons observed here.

\section{mGluR2/3 Therapy}

In the past several years, group II metabotropic glutamate receptors have become a target of potential therapeutics. Activation of these mGlur $2 / 3$ receptors can suppress presynaptic glutamate release in a negative feedback manner to keep glutamate transmission within a normal physiological range (Kew et al 2001; Scanziani et al 1997; Schoepp 2001). The location of mGluR $2 / 3$ receptors at the periphery of the terminals allows monitoring of excess glutamate spillover from the active zone (Conn \& Pin 1997). Developing a ligand with in vivo activity is necessary for preventing the hyperexcitability from interfering with normal neuronal function. The first selective agonist developed was LY354740 (Monn et al 1997) followed by LY379268, the latter of which has enhanced affinity for mGluR2/3 receptors (Monn et al 1999; Schoepp 2001). Metabotropic GluR2/3 are negatively coupled to adenyl cyclase, and thus agonists inhibit the production of cAMP (Monn et al 1997). As a more potent agonist, LY379268 suppresses cAMP formation on a magnitude of two orders higher than LY354740 (Monn et al 1999). This same study also showed that LY35470 had equal affinity for mGluR2 and mGlur3, while LY379268 is more selective for mGluR3 (Monn et al 1999). The early studies of mGlur2/3 agonists looked at efficacy with regards to a benefit for neuroprotection and ischemia. It was shown that LY379268 protects neurons against NMDA toxicity in cell cultures (D'Onofrio et al 2001; Kingston et al 1999), and this 
benefit is linked to a reduced release of glutamate via presynaptic activation of the mGluR $2 / 3$ receptors. In contrast to the understanding of the function of presynaptic mGluR $2 / 3$ receptors, less is known about the role of metabotropic group II receptors in glial cells. It is known that mGluR3 receptors are expressed in glial cells, but there is no expression of mGluR2 (Liu et al 1998; Ohishi et al 1993). Since a function of glia is the synthesis and uptake of glutamate (Winder \& Conn 1996), it is likely that activation of these receptors by LY379268 results in significant functional benefits. The role of glial cells in neuroprotection was affirmed by Kingston et al (1999), where LY379268 was more effective in preventing excitotoxicity in mixed cultures with neuronal and glial cells rather than pure neuronal cultures. The neuroprotection potentially arises from the release of proteins such as TGF- $\beta$ which stem from the activation of glial mGluR3 (Bruno et al 1998). The beneficial effects of mGluR3 agonists come from activating the mitogen-activated protein (MAP) kinase and the PI-3-kinase pathways (D'Onofrio et al 2001). Corti et al (2007) expanded on these earlier studies with knock-out models of mGlu2/3 receptors and concluded that neuroprotection came about from mGluR3 activation by LY379268. It is probable that neuroprotection from the LY compound arises from a combination of activation of presynaptic mGlu2/3 receptors to inhibit glutamate release and glial mGluR3 release of trophic proteins.

The function of LY379268 at mGlur2/3 receptors at excitatory terminals not only offers neuroprotection as delineated above, but the benefit of the drug is also seen in other diseases where glutamate-mediated transmission plays a role. A mouse model of schizophrenia was developed on the observation that NMDA receptor antagonists such as phencyclidine (PCP) or ketamine can heighten preexisting schizophrenic symptoms, and is associated with excessive glutamate release in limbic regions (Jentsch \& Roth 1999; Lorrain et al 2003; Marino \& Conn 2002). Rodents treated with these NMDA antagonists have stereotyped hyperkinesia and increased forward locomotion (Moghaddam \& Adams 1998; Sturgeon et al 1979). Hyperlocomotion associated with PCP or ketamine induction is reversed with LY379268 (Clark et al 2002; Imre et al 2006; Lorrain et al 2003). Motor behaviors are associated with an activated dopamine system (Creese \& Iversen 1973), and increased dopamine release is a factor in the actions of PCP (Freeman \& Bunney 1984). In order to eliminate the possibility of dopamine release as the cause of improved behavioral phenotypes, recent studies with rats that are deficient in serotonin and dopamine shows that the improved locomotor benefit of LY379268 stems from a reduction of evoked glutamate release (Chartoff et al 2005; Swanson et al 2005). More recently, another mGlur2/3 agonist, LY404039 was used in a double-blind, placebo-controlled Phase 2 clinical trial for schizophrenia. The outcome of the study showed statistically significant improvements of symptoms relative to psychopathology (Patil et al 2007). This clinical trial also showed that LY404039 was safe and well tolerated, and it was just as effective as olanzapine with regards to improvement of schizophrenic symptoms (Patil et al 2007).

Recent evidence suggests increased glutamate-mediated transmission, in addition to dopamine transmission, might play a role in regulating behavioral actions of drug abuse. Locomotor activity is increased by cocaine under conditions of administration with a conditioned stimulus (Hotsenpiller et al 2001). This study also found increased 
levels of glutamate in the nucleus accumbens via microdialysis (Hotsenpiller et al 2001). Conditioned drug-seeking behaviors brought about by cocaine or heroin are reversed with systemic LY379268 (Baptista et al 2004; Bossert et al 2004, 2006; Peters \& Kalivas 2006). Intraperitoneal injections of the LY compound also reduced hyperlocomotion induced from toluene in rats (Riegel et al 2003). Toluene is a solvent found in many inhaled substances that have abuse potential (Miyagawa et al 1984; Riegel et al 2003). Thus, LY379268 may show benefit in treating drug addiction, since it was effective in reducing drug seeking behavior.

Treatment of R6/2 mice with LY379268 has been shown in the present studies to be beneficial with regards to improvement of motor behavior and neurochemical endpoints. Earlier studies have shown that LY379268 is effective in treating neurodegenerative and psychiatric disorders that are associated with increased glutamate transmission. As a newer mGlur $2 / 3$ agonist, it has greater affinity and bioavailability than the previous generation. Moreover, a newer generation of the mGlur $2 / 3$ agonists, LY404039 has been through Phase II of a clinical trial. The outcome of the trial showed that the drug is safe and effective. LY404039 could soon move to Phase III clinical trials, if it is also shown effective R6/2 mice as well as in a genetically more precise model of $\mathrm{HD}$ as the YAC128 or the Q140. These results give credence to the choice of mGluR2/3 agonists as a therapy in diseases where increased glutamate is the underlying cause of the pathology. 


\section{LIST OF REFERENCES}

Albin RL, Reiner A, Anderson KD, Dure LS, Handelin B, et al. 1992. Preferential loss of striato-external pallidal projection neurons in presymptomatic Huntington's disease. Ann Neurol 31:425-30

Albin RL, Young AB, Penney JB, Handelin B, Balfour R, et al. 1990. Abnormalities of striatal projection neurons and $\mathrm{N}$-methyl-D-aspartate receptors in presymptomatic Huntington's disease. N Engl J Med 322:1293-8

Alexander GE, Crutcher MD. 1990. Functional architecture of basal ganglia circuits: neural substrates of parallel processing. Trends Neurosci 13:266-71

Almeida S, Brett AC, Gois IN, Oliveira CR, Rego AC. 2006. Caspase-dependent and independent cell death induced by 3-nitropropionic acid in rat cortical neurons. $J$ Cell Biochem 98:93-101

Altar CA, Cai N, Bliven T, Juhasz M, Conner JM, et al. 1997. Anterograde transport of brain-derived neurotrophic factor and its role in the brain. Nature 389:856-60

Anderson KD, Reiner A. 1990. Extensive co-occurrence of substance P and dynorphin in striatal projection neurons: an evolutionarily conserved feature of basal ganglia organization. J Comp Neurol 295:339-69

Andre VM, Cepeda C, Venegas A, Gomez Y, Levine MS. 2006. Altered cortical glutamate receptor function in the r6/2 model of Huntington's disease. $J$ Neurophysio 95:2108-19

Apostol BL, Kazantsev A, Raffioni S, Illes K, Pallos J, et al. 2003. A cell-based assay for aggregation inhibitors as therapeutics of polyglutamine-repeat disease and validation in Drosophila. Proc Natl Acad Sci U S A 100:5950-5

Baptista MA, Martin-Fardon R, Weiss F. 2004. Preferential effects of the metabotropic glutamate $2 / 3$ receptor agonist LY379268 on conditioned reinstatement versus primary reinforcement: comparison between cocaine and a potent conventional reinforcer. J Neurosci 24:4723-7

Baquet ZC, Gorski JA, Jones KR. 2004. Early striatal dendrite deficits followed by neuron loss with advanced age in the absence of anterograde cortical brainderived neurotrophic factor. $J$ Neurosci 24:4250-8

Battaglia G, Monn JA, Schoepp DD. 1997. In vivo inhibition of veratridine-evoked release of striatal excitatory amino acids by the group II metabotropic glutamate receptor agonist LY354740 in rats. Neurosci Lett 229:161-4

Beal MF, Brouillet E, Jenkins BG, Ferrante RJ, Kowall NW, et al. 1993. Neurochemical and histologic characterization of striatal excitotoxic lesions produced by the mitochondrial toxin 3-nitropropionic acid. J Neurosci 13:4181-92

Behrens PF, Franz P, Woodman B, Lindenberg KS, Landwehrmeyer GB. 2002. Impaired glutamate transport and glutamate-glutamine cycling: downstream effects of the Huntington mutation. Brain 125:1908-22

Berliocchi L, Bano D, Nicotera P. 2005. Ca2+ signals and death programmes in neurons. Philos Trans R Soc Lond B Biol Sci 360:2255-8

Bliss TV, Collingridge GL. 1993. A synaptic model of memory: long-term potentiation in the hippocampus. Nature 361:31-9 
Bolivar VJ, Manley K, Messer A. 2003. Exploratory activity and fear conditioning abnormalities develop early in R6/2 Huntington's disease transgenic mice. Behav Neurosci 117:1233-42

Bond A, Ragumoorthy N, Monn JA, Hicks CA, Ward MA, et al. 1999. LY379268, a potent and selective Group II metabotropic glutamate receptor agonist, is neuroprotective in gerbil global, but not focal, cerebral ischaemia. Neurosci Lett 273:191-4

Bossert JM, Gray SM, Lu L, Shaham Y. 2006. Activation of group II metabotropic glutamate receptors in the nucleus accumbens shell attenuates context-induced relapse to heroin seeking. Neuropsychopharmacology 31:2197-209

Bossert JM, Liu SY, Lu L, Shaham Y. 2004. A role of ventral tegmental area glutamate in contextual cue-induced relapse to heroin seeking. J Neurosci 24:10726-30

Bouras C, Vallet PG, Hof PR. 1991. Asymmetric increase in substance P immunoreactivity in the rat and guinea pig substantia nigra after unilateral neocortical ablation. Neurosci Lett 133:53-6

Bruno V, Battaglia G, Casabona G, Copani A, Caciagli F, Nicoletti F. 1998. Neuroprotection by glial metabotropic glutamate receptors is mediated by transforming growth factor-beta. J Neurosci 18:9594-600

Bruno V, Sureda FX, Storto M, Casabona G, Caruso A, et al. 1997. The neuroprotective activity of group-II metabotropic glutamate receptors requires new protein synthesis and involves a glial-neuronal signaling. J Neurosci 17:1891-7

Cai Z, Xiao F, Fratkin JD, Rhodes PG. 1999. Protection of neonatal rat brain from hypoxic-ischemic injury by LY379268, a Group II metabotropic glutamate receptor agonist. Neuroreport 10:3927-31

Calabresi P, Pisani A, Mercuri NB, Bernardi G. 1996. The corticostriatal projection: from synaptic plasticity to dysfunctions of the basal ganglia. Trends Neurosci 19:19-24

Camins A, Verdaguer E, Folch J, Beas-Zarate C, Canudas AM, Pallas M. 2007. Inhibition of ataxia telangiectasia-p53-E2F-1 pathway in neurons as a target for the prevention of neuronal apoptosis. Curr Drug Metab 8:709-15

Canals JM, Pineda JR, Torres-Peraza JF, Bosch M, Martin-Ibanez R, et al. 2004. Brainderived neurotrophic factor regulates the onset and severity of motor dysfunction associated with enkephalinergic neuronal degeneration in Huntington's disease. $J$ Neurosci 24:7727-39

Carter RJ, Lione LA, Humby T, Mangiarini L, Mahal A, et al. 1999. Characterization of progressive motor deficits in mice transgenic for the human Huntington's disease mutation. J Neurosci 19:3248-57

Cepeda C, Ariano MA, Calvert CR, Flores-Hernandez J, Chandler SH, et al. 2001. NMDA receptor function in mouse models of Huntington disease. J Neurosci Res 66:525-39

Cepeda C, Hurst RS, Calvert CR, Hernandez-Echeagaray E, Nguyen OK, et al. 2003. Transient and progressive electrophysiological alterations in the corticostriatal pathway in a mouse model of Huntington's disease. $J$ Neurosci 23:961-9

Cepeda C, Wu NP, Andre VM, Cummings DM, Levine MS. 2007. The corticostriatal pathway in Huntington's disease. Prog Neurobio 81:253-71

Cha JH. 2000. Transcriptional dysregulation in Huntington's disease. Trends Neurosci $23: 387-92$ 
Cha JH, Kosinski CM, Kerner JA, Alsdorf SA, Mangiarini L, et al. 1998. Altered brain neurotransmitter receptors in transgenic mice expressing a portion of an abnormal human huntington disease gene. Proc Natl Acad Sci U S A 95:6480-5

Charpier S, Deniau JM. 1997. In vivo activity-dependent plasticity at cortico-striatal connections: evidence for physiological long-term potentiation. Proc Natl Acad Sci U S A 94:7036-40

Chartoff EH, Heusner CL, Palmiter RD. 2005. Dopamine is not required for the hyperlocomotor response to NMDA receptor antagonists. Neuropsychopharmacology 30:1324-33

Clark M, Johnson BG, Wright RA, Monn JA, Schoepp DD. 2002. Effects of the mGlu2/3 receptor agonist LY379268 on motor activity in phencyclidine-sensitized rats. Pharmacol Biochem Behav 73:339-46

Conn PJ, Pin JP. 1997. Pharmacology and functions of metabotropic glutamate receptors. Annu Rev Pharmacol Toxicol 37:205-37

Copani A, Bruno V, Battaglia G, Leanza G, Pellitteri R, et al. 1995. Activation of metabotropic glutamate receptors protects cultured neurons against apoptosis induced by beta-amyloid peptide. Mol Pharmacol 47:890-7

Corti C, Battaglia G, Molinaro G, Riozzi B, Pittaluga A, et al. 2007. The use of knockout mice unravels distinct roles for mGlu2 and mGlu3 metabotropic glutamate receptors in mechanisms of neurodegeneration/neuroprotection. $J$ Neurosci 27:8297-308

Cortright JJ, Rebec GV. 2006. Ascorbate modulation of sensorimotor processing in striatum of freely moving rats. Brain Res 1092:108-16

Cozzi A, Attucci S, Peruginelli F, Marinozzi M, Luneia R, et al. 1997. Type 2 metabotropic glutamate ( $\mathrm{mGlu}$ ) receptors tonically inhibit transmitter release in rat caudate nucleus: in vivo studies with (2S, 1'S,2'S,3'R)-2-(2'-carboxy-3'phenylcyclopropyl)glycine, a new potent and selective antagonist. Eur J Neurosci 9:1350-5

Crawley JN. 1999. Behavioral phenotyping of transgenic and knockout mice: experimental design and evaluation of general health, sensory functions, motor abilities, and specific behavioral tests. Brain Res 835:18-26

Creese I, Iversen SD. 1973. Blockage of amphetamine induced motor stimulation and stereotypy in the adult rat following neonatal treatment with 6-hydroxydopamine. Brain Res 55:369-82

Cui L, Jeong H, Borovecki F, Parkhurst CN, Tanese N, Krainc D. 2006. Transcriptional repression of PGC-1alpha by mutant huntingtin leads to mitochondrial dysfunction and neurodegeneration. Cell 127:59-69

D'Onofrio M, Cuomo L, Battaglia G, Ngomba RT, Storto M, et al. 2001. Neuroprotection mediated by glial group-II metabotropic glutamate receptors requires the activation of the MAP kinase and the phosphatidylinositol-3-kinase pathways. $J$ Neurochem 78:435-45

Datto MB, Li Y, Panus JF, Howe DJ, Xiong Y, Wang XF. 1995. Transforming growth factor beta induces the cyclin-dependent kinase inhibitor p21 through a p53independent mechanism. Proc Natl Acad Sci U S A 92:5545-9 
Davies CH, Clarke VR, Jane DE, Collingridge GL. 1995. Pharmacology of postsynaptic metabotropic glutamate receptors in rat hippocampal CA1 pyramidal neurones. $\mathrm{Br}$ J Pharmacol 116:1859-69

Davies SW, Turmaine M, Cozens BA, DiFiglia M, Sharp AH, et al. 1997. Formation of neuronal intranuclear inclusions underlies the neurological dysfunction in mice transgenic for the HD mutation. Cell 90:537-48

DeLong MR. 1990. Primate models of movement disorders of basal ganglia origin. Trends Neurosci 13:281-5

Deng YP, Albin RL, Penney JB, Young AB, Anderson KD, Reiner A. 2004. Differential loss of striatal projection systems in Huntington's disease: a quantitative immunohistochemical study. J Chem Neuroanat 27:143-64

Di Liberto V, Bonomo A, Frinchi M, Belluardo N, Mudo G. 2010. Group II metabotropic glutamate receptor activation by agonist LY379268 treatment increases the expression of brain derived neurotrophic factor in the mouse brain. Neuroscience 165:863-73

DiFiglia M. 1990. Excitotoxic injury of the neostriatum - a model for Huntington's disease. Trends in Neurosciences 13:286-9

DiFiglia M, Sapp E, Chase K, Schwarz C, Meloni A, et al. 1995. Huntingtin is a cytoplasmic protein associated with vesicles in human and rat brain neurons. Neuron 14:1075-81

DiFiglia M, Sapp E, Chase KO, Davies SW, Bates GP, et al. 1997. Aggregation of huntingtin in neuronal intranuclear inclusions and dystrophic neurites in brain. Science 277:1990-3

Dragatsis I, Efstratiadis A, Zeitlin S. 1998. Mouse mutant embryos lacking huntingtin are rescued from lethality by wild-type extraembryonic tissues. Development 125:1529-39

Drai D, Golani I. 2001. SEE: a tool for the visualization and analysis of rodent exploratory behavior. Neurosci Biobehav Rev 25:409-26

Duyao MP, Auerbach AB, Ryan A, Persichetti F, Barnes GT, et al. 1995. Inactivation of the mouse Huntington's disease gene homolog Hdh. Science 269:407-10

Fan MM, Fernandes HB, Zhang LY, Hayden MR, Raymond LA. 2007. Altered NMDA receptor trafficking in a yeast artificial chromosome transgenic mouse model of Huntington's disease. J Neurosci 27:3768-79

Fan MM, Raymond LA. 2007. N-methyl-D-aspartate (NMDA) receptor function and excitotoxicity in Huntington's disease. Prog Neurobiol 81:272-93

Figueredo-Cardenas G, Anderson KD, Chen Q, Veenman CL, Reiner A. 1994. Relative survival of striatal projection neurons and interneurons after intrastriatal injection of quinolinic acid in rats. Exp Neurol 129:37-56

Freeman AS, Bunney BS. 1984. The effects of phencyclidine and N-allylnormetazocine on midbrain dopamine neuronal activity. Eur J Pharmacol 104:287-93

Freeman RS, Estus S, Johnson EM, Jr. 1994. Analysis of cell cycle-related gene expression in postmitotic neurons: selective induction of Cyclin D1 during programmed cell death. Neuron 12:343-55

Fusco FR, Zuccato C, Tartari M, Martorana A, De March Z, et al. 2003. Co-localization of brain-derived neurotrophic factor (BDNF) and wild-type huntingtin in normal and quinolinic acid-lesioned rat brain. Eur J Neurosci 18:1093-102 
Gauthier LR, Charrin BC, Borrell-Pages M, Dompierre JP, Rangone H, et al. 2004. Huntingtin controls neurotrophic support and survival of neurons by enhancing BDNF vesicular transport along microtubules. Cell 118:127-38

Gerfen CR, Engber TM, Mahan LC, Susel Z, Chase TN, et al. 1990. D1 and D2 dopamine receptor-regulated gene expression of striatonigral and striatopallidal neurons. Science 250:1429-32

Gervais FG, Singaraja R, Xanthoudakis S, Gutekunst CA, Leavitt BR, et al. 2002. Recruitment and activation of caspase- 8 by the Huntingtin-interacting protein Hip-1 and a novel partner Hippi. Nat Cell Biol 4:95-105

Gharami K, Xie Y, An JJ, Tonegawa S, Xu B. 2008. Brain-derived neurotrophic factor over-expression in the forebrain ameliorates Huntington's disease phenotypes in mice. J Neurochem 105:369-79

Gines S, Seong IS, Fossale E, Ivanova E, Trettel F, et al. 2003. Specific progressive cAMP reduction implicates energy deficit in presymptomatic Huntington's disease knock-in mice. Hum Mol Genet 12:497-508

Group HsDCR. 1993. A novel gene containing a trinucleotide repeat that is expanded and unstable on Huntington's disease chromosomes. The Huntington's Disease Collaborative Research Group. Cell 72:971-83

Grunewald RA, Fillenz M. 1984. Release of ascorbate from a synaptosomal fraction of rat brain. Neurochem Int 6:491-500

Gutekunst CA, Li SH, Yi H, Ferrante RJ, Li XJ, Hersch SM. 1998. The cellular and subcellular localization of huntingtin-associated protein 1 (HAP1): comparison with huntingtin in rat and human. $J$ Neurosci 18:7674-86

Hassel B, Tessler S, Faull RL, Emson PC. 2008. Glutamate uptake is reduced in prefrontal cortex in Huntington's disease. Neurochem Res 33:232-7

Hedreen JC, Peyser CE, Folstein SE, Ross CA. 1991. Neuronal loss in layers V and VI of cerebral cortex in Huntington's disease. Neurosci Lett 133:257-61

Herrup K, Busser JC. 1995. The induction of multiple cell cycle events precedes targetrelated neuronal death. Development 121:2385-95

Hodgson JG, Agopyan N, Gutekunst CA, Leavitt BR, LePiane F, et al. 1999. A YAC mouse model for Huntington's disease with full-length mutant huntingtin, cytoplasmic toxicity, and selective striatal neurodegeneration. Neuron 23:181-92

Hotsenpiller G, Giorgetti M, Wolf ME. 2001. Alterations in behaviour and glutamate transmission following presentation of stimuli previously associated with cocaine exposure. Eur J Neurosci 14:1843-55

Huang K, Yanai A, Kang R, Arstikaitis P, Singaraja RR, et al. 2004. Huntingtininteracting protein HIP14 is a palmitoyl transferase involved in palmitoylation and trafficking of multiple neuronal proteins. Neuron 44:977-86

Humbert S, Bryson EA, Cordelieres FP, Connors NC, Datta SR, et al. 2002. The IGF1/Akt pathway is neuroprotective in Huntington's disease and involves Huntingtin phosphorylation by Akt. Dev Cell 2:831-7

Imre G, Salomons A, Jongsma M, Fokkema DS, Den Boer JA, Ter Horst GJ. 2006. Effects of the mGluR2/3 agonist LY379268 on ketamine-evoked behaviours and neurochemical changes in the dentate gyrus of the rat. Pharmacol Biochem Behav $84: 392-9$ 
Jentsch JD, Roth RH. 1999. The neuropsychopharmacology of phencyclidine: from NMDA receptor hypofunction to the dopamine hypothesis of schizophrenia. Neuropsychopharmacology 20:201-25

Joshi PR, Wu NP, Andre VM, Cummings DM, Cepeda C, et al. 2009. Age-dependent alterations of corticostriatal activity in the YAC128 mouse model of Huntington disease. J Neurosci 29:2414-27

Kalchman MA, Graham RK, Xia G, Koide HB, Hodgson JG, et al. 1996. Huntingtin is ubiquitinated and interacts with a specific ubiquitin-conjugating enzyme. $\mathrm{J} \mathrm{Biol}$ Chem 271:19385-94

Kew JN, Ducarre JM, Pflimlin MC, Mutel V, Kemp JA. 2001. Activity-dependent presynaptic autoinhibition by group II metabotropic glutamate receptors at the perforant path inputs to the dentate gyrus and CA1. Neuropharmacology 40:20-7

King AE, Liu XH. 1996. Dual action of metabotropic glutamate receptor agonists on neuronal excitability and synaptic transmission in spinal ventral horn neurons in vitro. Neuropharmacology 35:1673-80

Kingston AE, O'Neill MJ, Lam A, Bales KR, Monn JA, Schoepp DD. 1999. Neuroprotection by metabotropic glutamate receptor glutamate receptor agonists: LY354740, LY379268 and LY389795. Eur J Pharmacol 377:155-65

Krantic S, Mechawar N, Reix S, Quirion R. 2005. Molecular basis of programmed cell death involved in neurodegeneration. Trends Neurosci 28:670-6

Kuhn A, Goldstein DR, Hodges A, Strand AD, Sengstag T, et al. 2007. Mutant huntingtin's effects on striatal gene expression in mice recapitulate changes observed in human Huntington's disease brain and do not differ with mutant huntingtin length or wild-type huntingtin dosage. Hum Mol Genet 16:1845-61

Laforet GA, Sapp E, Chase K, McIntyre C, Boyce FM, et al. 2001. Changes in cortical and striatal neurons predict behavioral and electrophysiological abnormalities in a transgenic murine model of Huntington's disease. Journal of Neuroscience 21:9112-23

Lei W, Jiao Y, Del Mar N, Reiner A. 2004. Evidence for differential cortical input to direct pathway versus indirect pathway striatal projection neurons in rats. $J$ Neurosci 24:8289-99

Lessmann V, Gottmann K, Malcangio M. 2003. Neurotrophin secretion: current facts and future prospects. Prog Neurobiol 69:341-74

Levine MS, Klapstein GJ, Koppel A, Gruen E, Cepeda C, et al. 1999. Enhanced sensitivity to N-methyl-D-aspartate receptor activation in transgenic and knockin mouse models of Huntington's disease. J Neurosci Res 58:515-32

Li H, Li SH, Cheng AL, Mangiarini L, Bates GP, Li XJ. 1999. Ultrastructural localization and progressive formation of neuropil aggregates in Huntington's disease transgenic mice. Hum Mol Genet 8:1227-36

Li L, Murphy TH, Hayden MR, Raymond LA. 2004. Enhanced striatal NR2B-containing N-methyl-D-aspartate receptor-mediated synaptic currents in a mouse model of Huntington disease. J Neurophysiol 92:2738-46

Li SH, Li XJ. 2004a. Huntingtin-protein interactions and the pathogenesis of Huntington's disease. Trends Genet 20:146-54

Li SH, Li XJ. 2004b. Huntingtin and its role in neuronal degeneration. Neuroscientist $10: 467-75$ 
Lievens JC, Bernal F, Forni C, Mahy N, Kerkerian-Le Goff L. 2000. Characterization of striatal lesions produced by glutamate uptake alteration: cell death, reactive gliosis, and changes in GLT1 and GADD45 mRNA expression. Glia 29:222-32

Lievens JC, Woodman B, Mahal A, Spasic-Boscovic O, Samuel D, et al. 2001. Impaired glutamate uptake in the R6 Huntington's disease transgenic mice. Neurobiol Dis 8:807-21

Lisman JE. 1997. Bursts as a unit of neural information: making unreliable synapses reliable. Trends Neurosci 20:38-43

Liu XB, Munoz A, Jones EG. 1998. Changes in subcellular localization of metabotropic glutamate receptor subtypes during postnatal development of mouse thalamus. $J$ Comp Neurol 395:450-65

Lorrain DS, Baccei CS, Bristow LJ, Anderson JJ, Varney MA. 2003. Effects of ketamine and N-methyl-D-aspartate on glutamate and dopamine release in the rat prefrontal cortex: modulation by a group II selective metabotropic glutamate receptor agonist LY379268. Neuroscience 117:697-706

Luesse HG, Schiefer J, Spruenken A, Puls C, Block F, Kosinski CM. 2001. Evaluation of R6/2 HD transgenic mice for therapeutic studies in Huntington's disease: behavioral testing and impact of diabetes mellitus. Behav Brain Res 126:185-95

Luthi-Carter R, Strand A, Peters NL, Solano SM, Hollingsworth ZR, et al. 2000. Decreased expression of striatal signaling genes in a mouse model of Huntington's disease. Hum Mol Genet 9:1259-71

MacDonald EA. 1993. A novel gene containing a trinucleotide repeat that is expanded and unstable on Huntington's disease chromosomes. The Huntington's Disease Collaborative Research Group. Cell 72:971-83

Mangiarini L, Sathasivam K, Seller M, Cozens B, Harper A, et al. 1996. Exon 1 of the HD gene with an expanded CAG repeat is sufficient to cause a progressive neurological phenotype in transgenic mice. Cell 87:493-506

Marino MJ, Conn PJ. 2002. Direct and indirect modulation of the N-methyl D-aspartate receptor. Curr Drug Targets CNS Neurol Disord 1:1-16

Massaous J, Hata A. 1997. TGF-beta signalling through the Smad pathway. Trends Cell Biol 7:187-92

McCool BA, Pin JP, Brust PF, Harpold MM, Lovinger DM. 1996. Functional coupling of rat group II metabotropic glutamate receptors to an omega-conotoxin GVIAsensitive calcium channel in human embryonic kidney 293 cells. Mol Pharmacol 50:912-22

Menalled L, Zanjani H, MacKenzie L, Koppel A, Carpenter E, et al. 2000. Decrease in striatal enkephalin mRNA in mouse models of Huntington's disease. Experimental Neurology 162:328-42

Miller BR, Walker AG, Shah AS, Barton SJ, Rebec GV. 2008. Dysregulated information processing by medium spiny neurons in striatum of freely behaving mouse models of Huntington's disease. J Neurophysiol 100:2205-16

Milnerwood AJ, Gladding CM, Pouladi MA, Kaufman AM, Hines RM, et al. 2010. Early increase in extrasynaptic NMDA receptor signaling and expression contributes to phenotype onset in Huntington's disease mice. Neuron 65:178-90

Miyagawa M, Honma T, Sato M, Hasegawa H. 1984. Effects of single exposure to toluene on operant behavior and brain toluene levels in rats. Ind Health 22:127-31 
Moghaddam B, Adams BW. 1998. Reversal of phencyclidine effects by a group II metabotropic glutamate receptor agonist in rats. Science 281:1349-52

Monn JA, Valli MJ, Massey SM, Hansen MM, Kress TJ, et al. 1999. Synthesis, pharmacological characterization, and molecular modeling of heterobicyclic amino acids related to (+)-2-aminobicyclo[3.1.0] hexane-2,6-dicarboxylic acid (LY354740): identification of two new potent, selective, and systemically active agonists for group II metabotropic glutamate receptors. $J$ Med Chem 42:1027-40

Monn JA, Valli MJ, Massey SM, Wright RA, Salhoff CR, et al. 1997. Design, synthesis, and pharmacological characterization of (+)-2-aminobicyclo[3.1.0]hexane-2,6dicarboxylic acid (LY354740): a potent, selective, and orally active group 2 metabotropic glutamate receptor agonist possessing anticonvulsant and anxiolytic properties. J Med Chem 40:528-37

Monsma FJ, Jr., Mahan LC, McVittie LD, Gerfen CR, Sibley DR. 1990. Molecular cloning and expression of a D1 dopamine receptor linked to adenylyl cyclase activation. Proc Natl Acad Sci U S A 87:6723-7

Murphy KP, Carter RJ, Lione LA, Mangiarini L, Mahal A, et al. 2000. Abnormal synaptic plasticity and impaired spatial cognition in mice transgenic for exon 1 of the human Huntington's disease mutation. J Neurosci 20:5115-23

Nakanishi S. 1992. Molecular diversity of glutamate receptors and implications for brain function. Science 258:597-603

Nucifora FC, Jr., Sasaki M, Peters MF, Huang H, Cooper JK, et al. 2001. Interference by huntingtin and atrophin-1 with cbp-mediated transcription leading to cellular toxicity. Science 291:2423-8

Ohishi H, Shigemoto R, Nakanishi S, Mizuno N. 1993. Distribution of the mRNA for a metabotropic glutamate receptor (mGluR3) in the rat brain: an in situ hybridization study. J Comp Neurol 335:252-66

Okamoto S, Pouladi MA, Talantova M, Yao D, Xia P, et al. 2009. Balance between synaptic versus extrasynaptic NMDA receptor activity influences inclusions and neurotoxicity of mutant huntingtin. Nat Med 15:1407-13

Papadia S, Soriano FX, Leveille F, Martel MA, Dakin KA, et al. 2008. Synaptic NMDA receptor activity boosts intrinsic antioxidant defenses. Nat Neurosci 11:476-87

Patil ST, Zhang L, Martenyi F, Lowe SL, Jackson KA, et al. 2007. Activation of mGlu2/3 receptors as a new approach to treat schizophrenia: a randomized Phase 2 clinical trial. Nat Med 13:1102-7

Pelegri C, Duran-Vilaregut J, del Valle J, Crespo-Biel N, Ferrer I, et al. 2008. Cell cycle activation in striatal neurons from Huntington's disease patients and rats treated with 3-nitropropionic acid. Int J Dev Neurosci 26:665-71

Peters J, Kalivas PW. 2006. The group II metabotropic glutamate receptor agonist, LY379268, inhibits both cocaine- and food-seeking behavior in rats.

Psychopharmacology (Berl) 186:143-9

Poirier MA, Jiang H, Ross CA. 2005. A structure-based analysis of huntingtin mutant polyglutamine aggregation and toxicity: evidence for a compact beta-sheet structure. Hum Mol Genet 14:765-74

Poo MM. 2001. Neurotrophins as synaptic modulators. Nat Rev Neurosci 2:24-32 
Rebec GV, Barton SJ, Ennis MD. 2002. Dysregulation of ascorbate release in the striatum of behaving mice expressing the Huntington's disease gene. Journal of Neuroscience 22:1-5

Rebec GV, Witowski SR, Sandstrom MI, Rostand RD, Kennedy RT. 2005. Extracellular ascorbate modulates cortically evoked glutamate dynamics in rat striatum. Neurosci Lett 378:166-70

Reddy PH, Williams M, Tagle DA. 1999. Recent advances in understanding the pathogenesis of Huntington's disease. Trends Neurosci 22:248-55

Reiner A, Albin RL, Anderson KD, D'Amato CJ, Penney JB, Young AB. 1988. Differential loss of striatal projection neurons in Huntington disease. Proc Natl Acad Sci U S A 85:5733-7

Ren RF, Hawver DB, Kim RS, Flanders KC. 1997. Transforming growth factor-beta protects human hNT cells from degeneration induced by beta-amyloid peptide: involvement of the TGF-beta type II receptor. Brain Res Mol Brain Res 48:31522

Rice ME. 2000. Ascorbate regulation and its neuroprotective role in the brain. Trends Neurosci 23:209-16

Riegel AC, Ali SF, French ED. 2003. Toluene-induced locomotor activity is blocked by 6-hydroxydopamine lesions of the nucleus accumbens and the mGluR2/3 agonist LY379268. Neuropsychopharmacology 28:1440-7

Rigamonti D, Bauer JH, De-Fraja C, Conti L, Sipione S, et al. 2000. Wild-type huntingtin protects from apoptosis upstream of caspase-3. J Neurosci 20:3705-13

Sakurai Y. 1999. How do cell assemblies encode information in the brain? Neurosci Biobehav Rev 23:785-96

Salinas E, Sejnowski TJ. 2001. Correlated neuronal activity and the flow of neural information. Nat Rev Neurosci 2:539-50

Sapp E, Ge P, Aizawa H, Bird E, Penney J, et al. 1995. Evidence for a preferential loss of enkephalin immunoreactivity in the external globus pallidus in low grade Huntington's disease using high resolution image analysis. Neuroscience 64:397404

Scanziani M, Salin PA, Vogt KE, Malenka RC, Nicoll RA. 1997. Use-dependent increases in glutamate concentration activate presynaptic metabotropic glutamate receptors. Nature 385:630-4

Schiefer J, Sprunken A, Puls C, Luesse HG, Milkereit A, et al. 2004. The metabotropic glutamate receptor 5 antagonist MPEP and the mGluR2 agonist LY379268 modify disease progression in a transgenic mouse model of Huntington's disease. Brain Res 1019:246-54

Schilling G, Becher MW, Sharp AH, Jinnah HA, Duan K, et al. 1999. Intranuclear inclusions and neuritic aggregates in transgenic mice expressing a mutant $\mathrm{N}$ terminal fragment of huntingtin. Hum Mol Genet 8:397-407

Schoepp DD. 2001. Unveiling the functions of presynaptic metabotropic glutamate receptors in the central nervous system. J Pharmacol Exp Ther 299:12-20

Schoepp DD, Jane DE, Monn JA. 1999. Pharmacological agents acting at subtypes of metabotropic glutamate receptors. Neuropharmacology 38:1431-76

Sharp AH, Loev SJ, Schilling G, Li SH, Li XJ, et al. 1995. Widespread expression of Huntington's disease gene (IT15) protein product. Neuron 14:1065-74 
Shear DA, Dong J, Gundy CD, Haik-Creguer KL, Dunbar GL. 1998. Comparison of intrastriatal injections of quinolinic acid and 3-nitropropionic acid for use in animal models of Huntington's disease. Prog Neuropsychopharmacol Biol Psychiatry 22:1217-40

Shigeri Y, Seal RP, Shimamoto K. 2004. Molecular pharmacology of glutamate transporters, EAATs and VGLUTs. Brain Res Brain Res Rev 45:250-65

Shin JY, Fang ZH, Yu ZX, Wang CE, Li SH, Li XJ. 2005. Expression of mutant huntingtin in glial cells contributes to neuronal excitotoxicity. J Cell Biol 171:1001-12

Somers DL, Beckstead RM. 1990. Striatal preprotachykinin and preproenkephalin mRNA levels and the levels of nigral substance $\mathrm{P}$ and pallidal Met5-enkephalin depend on corticostriatal axons that use the excitatory amino acid neurotransmitters aspartate and glutamate: quantitative radioimmunocytochemical and in situ hybridization evidence. Brain Res Mol Brain Res 8:143-58

Stack EC, Dedeoglu A, Smith KM, Cormier K, Kubilus JK, et al. 2007. Neuroprotective effects of synaptic modulation in Huntington's disease R6/2 mice. J Neurosci 27:12908-15

Stack EC, Kubilus JK, Smith K, Cormier K, Del Signore SJ, et al. 2005. Chronology of behavioral symptoms and neuropathological sequela in R6/2 Huntington's disease transgenic mice. J Comp Neurol 490:354-70

Steffan JS, Agrawal N, Pallos J, Rockabrand E, Trotman LC, et al. 2004. SUMO modification of Huntingtin and Huntington's disease pathology. Science 304:1004

Strand AD, Baquet ZC, Aragaki AK, Holmans P, Yang L, et al. 2007. Expression profiling of Huntington's disease models suggests that brain-derived neurotrophic factor depletion plays a major role in striatal degeneration. J Neurosci 27:1175868

Sturgeon RD, Fessler RG, Meltzer HY. 1979. Behavioral rating scales for assessing phencyclidine-induced locomotor activity, stereotyped behavior and ataxia in rats. Eur J Pharmacol 59:169-79

Suarez I, Bodega G, Fernandez B. 2002. Glutamine synthetase in brain: effect of ammonia. Neurochem Int 41:123-42

Subramaniam S, Sixt KM, Barrow R, Snyder SH. 2009. Rhes, a striatal specific protein, mediates mutant-huntingtin cytotoxicity. Science 324:1327-30

Sun Z, Del Mar N, Meade C, Goldowitz D, Reiner A. 2002. Differential changes in striatal projection neurons in R6/2 transgenic mice for Huntington's disease. Neurobiol Dis 11:369-85

Swanson CJ, Bures M, Johnson MP, Linden AM, Monn JA, Schoepp DD. 2005. Metabotropic glutamate receptors as novel targets for anxiety and stress disorders. Nat Rev Drug Discov 4:131-44

Telenius H, Kremer HP, Theilmann J, Andrew SE, Almqvist E, et al. 1993. Molecular analysis of juvenile Huntington disease: the major influence on (CAG)n repeat length is the sex of the affected parent. Hum Mol Genet 2:1535-40

Testa CM, Standaert DG, Young AB, Penney JB, Jr. 1994. Metabotropic glutamate receptor mRNA expression in the basal ganglia of the rat. $J$ Neurosci 14:3005-18 
Thomas LB, Gates DJ, Richfield EK, O'Brien TF, Schweitzer JB, Steindler DA. 1995. DNA end labeling (TUNEL) in Huntington's disease and other neuropathological conditions. Exp Neurol 133:265-72

Velier J, Kim M, Schwarz C, Kim TW, Sapp E, et al. 1998. Wild-type and mutant huntingtins function in vesicle trafficking in the secretory and endocytic pathways. Experimental Neurology 152:34-40

Vonsattel JP, DiFiglia M. 1998. Huntington disease. J Neuropathol Exp Neurol 57:36984

Wellington CL, Ellerby LM, Gutekunst CA, Rogers D, Warby S, et al. 2002. Caspase cleavage of mutant huntingtin precedes neurodegeneration in Huntington's disease. $J$ Neurosci 22:7862-72

Widmer HR, Hefti F. 1994. Neurotrophin-4/5 promotes survival and differentiation of rat striatal neurons developing in culture. Eur J Neurosci 6:1669-79

Winder DG, Conn PJ. 1996. Roles of metabotropic glutamate receptors in glial function and glial-neuronal communication. $J$ Neurosci Res 46:131-7

Woods J, Snape M, Smith MA. 2007. The cell cycle hypothesis of Alzheimer's disease: suggestions for drug development. Biochim Biophys Acta 1772:503-8

Zhang Y, Leavitt BR, van Raamsdonk JM, Dragatsis I, Goldowitz D, et al. 2006. Huntingtin inhibits caspase-3 activation. EMBO J 25:5896-906

Zhu X, Lee HG, Perry G, Smith MA. 2007. Alzheimer disease, the two-hit hypothesis: an update. Biochim Biophys Acta 1772:494-502

Zuccato C, Cattaneo E. 2007. Role of brain-derived neurotrophic factor in Huntington's disease. Prog Neurobiol 81:294-330

Zuccato C, Ciammola A, Rigamonti D, Leavitt BR, Goffredo D, et al. 2001. Loss of huntingtin-mediated BDNF gene transcription in Huntington's disease. Science 293:493-8

Zuccato C, Liber D, Ramos C, Tarditi A, Rigamonti D, et al. 2005. Progressive loss of BDNF in a mouse model of Huntington's disease and rescue by BDNF delivery. Pharmacol Res 52:133-9 


\section{VITA}

Dennis Craig Lafferty was born in 1965 . He received his Bachelor of Science degree from Arizona State University in 1994. He was accepted to the William Scholl College of Podiatric Medicine that same year and received his Doctorate degree of Podiatric Medicine in 1998. A residency of Primary Podiatric Medicine and Surgery was completed in 2000 at the Central Alabama Veteran's Health Care System. He will graduate with his Master's degree of Neuroscience in December of 2010. 